\title{
Olig2-Targeted G-Protein-Coupled Receptor Gpr17 Regulates Oligodendrocyte Survival in Response to Lysolecithin-Induced Demyelination
}

\author{
Zhimin Ou, ${ }^{1 \star}$ Yuxia Sun, ${ }^{1 *}$ Li Lin, ${ }^{1 *}$ Nachun You, ${ }^{1}$ Xue Liu, ${ }^{1}{ }^{\oplus H o n g c h a o ~ L i, ~}{ }^{1}$ Yanchen Ma, ${ }^{1}$ Lei Cao, ${ }^{1}$ Ying Han, ${ }^{2}$ \\ ๑Min Liu, ${ }^{1}$ Yaqi Deng, ${ }^{3}$ Luming Yao, ${ }^{1} \mathbb{C}$. Richard Lu, ${ }^{3}$ and Ying Chen ${ }^{1}$ \\ ${ }^{1}$ State Key Laboratory of Cellular Stress Biology, School of Life Sciences, Xiamen University, Xiamen 361005, Fujian Province, China, ${ }^{2}$ The First Affiliated \\ Hospital of Xiamen University, Xiamen 361101, Fujian Province, China, and ${ }^{3}$ Cancer and Blood Disease Institute, Cincinnati Children's Hospital Medical \\ Center, Cincinnati, Ohio 45229
}

Demyelinating diseases, such as multiple sclerosis, are known to result from acute or chronic injury to the myelin sheath and inadequate remyelination; however, the underlying molecular mechanisms remain unclear. Here, we performed genome occupancy analysis by chromatin immunoprecipitation sequencing in oligodendrocytes in response to lysolecithin-induced injury and found that Olig2 and its downstream target Gpr17 are critical factors in regulating oligodendrocyte survival. After injury to oligodendrocytes, Olig2 was significantly upregulated and transcriptionally targeted the Gpr17 locus. Gpr17 activation inhibited oligodendrocyte survival by reducing the intracellular cAMP level and inducing expression of the pro-apoptotic gene Xaf1. The protein kinase A signaling pathway and the transcription factor c-Fos mediated the regulatory effects of Gpr17 in oligodendrocytes. We showed that Gpr17 inhibition elevated Epac1 expression and promoted oligodendrocyte differentiation. The loss of Gpr17, either globally or specifically in oligodendrocytes, led to an earlier onset of remyelination after myelin injury in mice. Similarly, pharmacological inhibition of Gpr17 with pranlukast promoted remyelination. Our findings indicate that Gpr17, an Olig2 transcriptional target, is activated after injury to oligodendrocytes and that targeted inhibition of Gpr17 promotes oligodendrocyte remyelination.

Key words: apoptosis; Gpr17; oligodendrocytes; remyelination

Significance Statement

Genome occupancy analysis of oligodendrocytes in response to lysolecithin-mediated demyelination injury revealed that 0lig2 and its downstream target Gpr17 are part of regulatory circuitry critical for oligodendrocyte survival. Gpr17 inhibits oligodendrocyte survival through activation of Xafl and cell differentiation by reducing Epacl expression. The loss of Gpr17 in mice led to precocious myelination and an earlier onset of remyelination after demyelination. Pharmacological inhibition of Gpr17 promoted remyelination, highlighting the potential for Gpr17-targeted therapeutic approaches in demyelination diseases.

\section{Introduction}

The myelin sheath formed by oligodendrocytes is necessary for normal function of the CNS. Myelination increases the speed of impulse propagation along nerve fibers (Baumann and PhamDinh, 2001), whereas demyelination impairs the integrity of myelin sheaths and therefore compromises saltatory conduction (Aktas et al., 2010; Fancy et al., 2011; Franklin and Gallo, 2014). Remyelination is necessary for recovery of proper nerve conduction after myelin injury and relies on the recruitment and proliferation of oligodendrocyte precursor cells (OPCs) and their maturation into myelin-producing oligodendrocytes (Pfeiffer et al., 1993; Franklin and ffrench-Constant, 2008). The maturation 
of oligodendrocytes is highly regulated by intracellular and extracellular factors. In demyelinating diseases such as multiple sclerosis, remyelination is interrupted because OPCs fail to mature, which contributes to axonal degeneration and irreversible neurological disabilities (Trapp et al., 1998; Berger et al., 2001). Targeting the immune system through immunomodulation results in limited induction of myelin repair in multiple sclerosis patients and has little effect on myelin repair and disease progression (Franklin and ffrench-Constant, 2008; Hartung and Aktas, 2011), indicating that alternative therapeutic interventions are needed to enhance remyelination. Several pathways for developmental regulation of myelination have been reported (Franklin and Gallo, 2014); however, strategies that enhance remyelination remain to be developed.

Gpr17 is an orphan G-protein-coupled receptor that responds to both uracil nucleotides and cysteinyl leukotrienes (cysLTs; Ciana et al., 2006). This receptor has a typical seven-transmembrane domain topology and shares $21-48 \%$ homology with $\mathrm{P} 2 \mathrm{Y}$ and cysLT receptors. The conserved $\mathrm{H}-\mathrm{X}-\mathrm{X}-\mathrm{R} / \mathrm{K}$ motif within the TM6 domain is crucial for Gpr17 ligand recognition (Lecca et al., 2008). Endogenous ligands of Gpr17, such as UDPglucose and cysLTs, have been identified, and synthetic ligands, such as MDL29951 and pranlukast, have been developed to activate or antagonize Gpr17 activity, respectively (Ciana et al., 2006; Lecca et al., 2008; Hennen et al., 2013).

Activation of Gpr17 signaling upregulates the expression of a differentiation inhibitor, ID2, and promotes the nuclear translocation of ID2 and ID4 (Chen et al., 2009). Overexpression of Gpr17 in the oligodendrocyte lineage causes defects in myelinogenesis in transgenic mice, and Gpr17 knock-out mice exhibit precocious myelination in the spinal cord at the neonatal stage (Chen et al., 2009). The hypothesis that activation of Gpr17 delays oligodendrocyte maturation is supported by recent findings that Gpr17 desensitization by G-protein receptor kinase phosphorylation and subsequent internalization are necessary for terminal differentiation of OPCs (Daniele et al., 2014). Furthermore, Gpr 17 has been shown to negatively regulate oligodendrocyte differentiation via the inactivation of intracellular protein kinase A (PKA) and cAMP-activated GTP exchange factor Epac1 (Simon et al., 2016).

In addition to the regulation of normal oligodendrocyte development, Gpr17 also functions as a sensor for extracellular damage signals under pathological conditions such as ischemia and brain trauma (Lecca et al., 2008; Ceruti et al., 2009; Boda et al., 2011; Zhao et al., 2012). A recent report indicates that Gpr17 antagonism results in structural and functional rejuvenation of aged brains, suggesting a promising clinical application for a Gpr17-based intervention (Marschallinger et al., 2015). In this study, using in vitro biochemical and in vivo mutagenesis approaches, we elucidated the role of Gpr17 in the survival and differentiation of oligodendrocytes in response to demyelinating injury induced by treatment with lysolecithin (LPC).

\section{Materials and Methods}

Animals. C57BL/6 mice were purchased from and maintained in the Xiamen University Laboratory Animal Center. Gpr $17^{-1-}$ mice were generated as described previously (Chen et al., 2009). The Gpr $17^{f l f l}$ mice were generated by Beijing Biocytogen Company. All mice were maintained in the Xiamen University Laboratory Animal Center. Animals of both sexes were used in the study, and littermates were used as controls. All of the animal experiments were approved by and performed according to the experimental guidelines of the Animal Care and Use Committee of Xiamen University.
$L P C$-induced demyelination. Mice were given stereotactic injections of $2 \mu \mathrm{l}$ of $1 \%(\mathrm{w} / \mathrm{v})$ LPC (Sigma) in $0.9 \% \mathrm{NaCl}$ into the corpus callosum (CC) as described previously (Chan et al., 2014) using the following coordinates: $0.3 \mathrm{~mm}$ anterior to bregma, $1 \mathrm{~mm}$ lateral to bregma, and $2.5 \mathrm{~mm}$ deep relative to the skull surface. For pharmacological Gpr17 antagonism, pranlukast $(0.1 \mathrm{mg} / \mathrm{kg})$ was intraperitoneally injected every $12 \mathrm{~h}$.

Cell culture. Primary rat OPCs were isolated from the cortices of pups at $\mathrm{P} 0-\mathrm{P} 2$ using a differential detachment procedure as described previously (Chen et al., 2007). The isolated rat OPCs were grown in OPC growth medium (Sato medium supplemented with $20 \mathrm{ng} / \mathrm{ml}$ PDGF-AA and $20 \mathrm{ng} / \mathrm{ml} \mathrm{bFGF)} \mathrm{and} \mathrm{differentiated} \mathrm{in} \mathrm{oligodendrocyte} \mathrm{differe-}$ ntiation medium (Sato medium supplemented with $15 \mathrm{~nm}$ of the thyroid hormone $\mathrm{T} 3$ and $10 \mathrm{ng} / \mathrm{ml}$ ciliary neurotrophic factor) for $4 \mathrm{~d}$ to maturation.

To examine expression of genes of interest in oligodendrocytes, OPCs were transfected with expression vectors carrying the gene of interest or transduced with the lentiviral vector pLL3.7 (catalog \#11795, Addgene) carrying shRNA targeting the gene of interest and differentiated in the presence of CNTF and T3 for $48 \mathrm{~h}$ before subsequent analyses. Oligodendrocytes derived from primary rat OPCs were treated with the compound of interest, including pranlukast (catalog \#HY-B0290, MedChem Express), MDL29951 (catalog \#HY-16312, MedChem Express), dibutyryl cAMP (catalog \#D0627, Sigma-Aldrich), H89 (catalog \#HY-15979, MedChem Express), KT5720 (catalog \#BML-EI199-0100, Enzo Life Sciences), and 3-[5-(tert-butyl)isoxazol-3-yl]-2-[2-(3-chlorophenyl)hydrazono] 3-oxopropanenitrile (ESI-09; catalog \#HY-16704, MedChem Express), and were cultured in differentiation medium for $48 \mathrm{~h}$ before subsequent experiments.

Antibodies. The antibodies used in immunofluorescent staining and Western blot procedures included Gpr17 (catalog \#10136, Cayman Chemical), MBP (catalog \#SMI-94R, Covance), Olig2 (catalog \#AB9610, Millipore), CC1 (catalog \#OP80, Calbiochem), PDGFR $\alpha$ (catalog \#SC338, Santa Cruz Biotechnology), GFAP (catalog \#3670, Cell Signaling Technology), Iba-1 (catalog \#019-19744, Wako), cleaved caspase 3 (catalog \#9661, Cell Signaling Technology), Xaf1 (catalog \#Ab17204, Abcam), NeuN (catalog \#Ab177487, Abcam), NG2 (catalog \#AB5320, Millipore), Epac1 (catalog \#4155, Cell Signaling Technology), c-Fos (catalog \#Ab7693, Abcam), phosphorylated PKA (catalog \#SC-32968, Santa Cruz Biotechnology), PKA (catalog \#SC-98951, Santa Cruz Biotechnology), and Gapdh (catalog \#60004-1-lg, Proteintech).

ChIP-Seq analysis. Chromatin immunoprecipitation (ChIP) assays were performed as described previously (Weng et al., 2012). The ChIPSeq peak calling and data analyses were performed as described previously (Yu et al., 2013). Briefly, five individual dishes of oligodendrocytes ( $\sim 20$ million cells) treated with or without LPC were pooled, and cells were fixed for $10 \mathrm{~min}$ at room temperature with $1 \%$ formaldehydecontaining medium. Nuclei were pelleted and sonicated in sonication buffer (10 mm Tris-HCl, pH 8.0, 1 mm EDTA, 0.5 mм EGTA, and protease inhibitor mixture). Sonicated chromatin $(300 \mathrm{mg})$ was incubated with the appropriate antibody $(4 \mathrm{mg})$ overnight at $4^{\circ} \mathrm{C}$. Of each ChIP reaction, $10 \%$ was kept as input DNA. Prerinsed protein A/G plus agarose beads $(50 \mathrm{ml})$ were added to each ChIP reaction and incubated for $1 \mathrm{~h}$ at room temperature. The beads were then incubated in $200 \mathrm{ml}$ of elution buffer at $65^{\circ} \mathrm{C}$ for $20 \mathrm{~min}$ to elute immunoprecipitated DNA. The ChIP-Seq libraries were prepared using a 5500 SOLiD Fragment Library Core kit (PN 4464412) and run on a 5500xl SOLiD Sequencer (Life Technologies). The number of reads per replicate were $\sim 6$ million (VehH3K27Ac), 11 million (LPC-H3K27Ac), 15 million (Veh-Olig2), and 13 million (LPC-Olig2). All sequencing data were mapped to the November 2004 rat genome assembly (Baylor 3.4/rn4), and peak calling was performed using Model-based Analysis of ChIP-Seq (MACS) version 1.4.2 (http://liulab.dfci.harvard.edu/MACS) with the default parameters to obtain the primary binding regions. For ChIP-Seq analysis, the background was subtracted, and the primary binding regions were filtered for (1) an enrichment of 3.5-fold and (2) a tag number $>25$. Data analyses were performed using the DBChIP algorithm as described previously (Liang and Keles, 2012). The ChIP-Seq data have been deposited into the GEO repository (accession number GSE84011). 
A

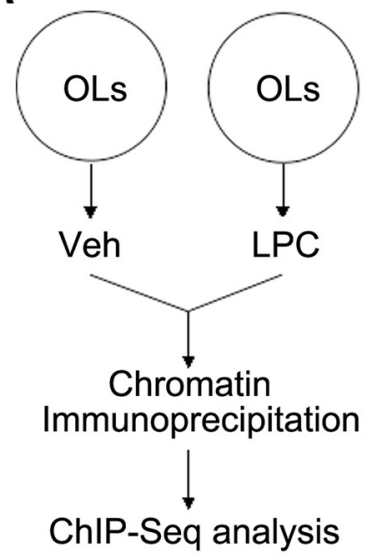

B

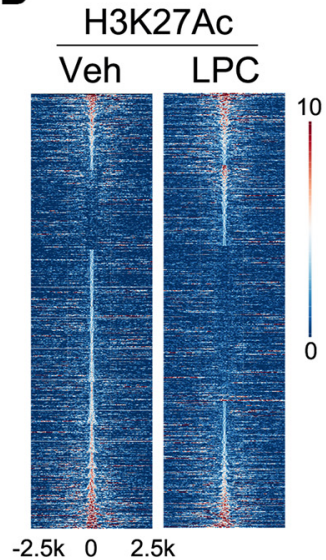

C

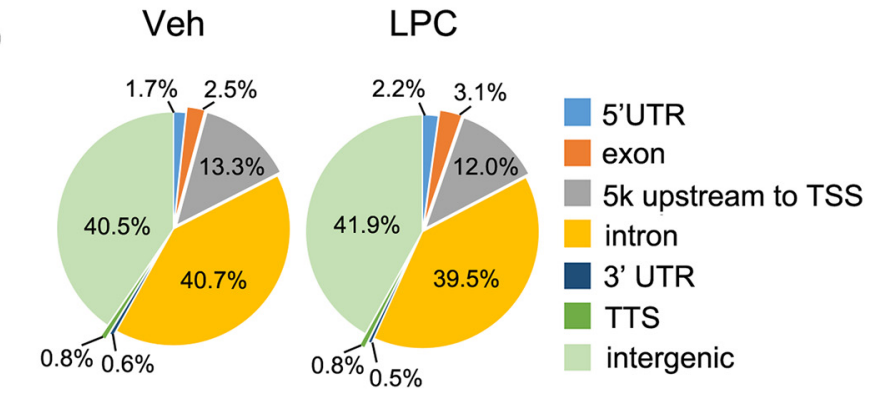

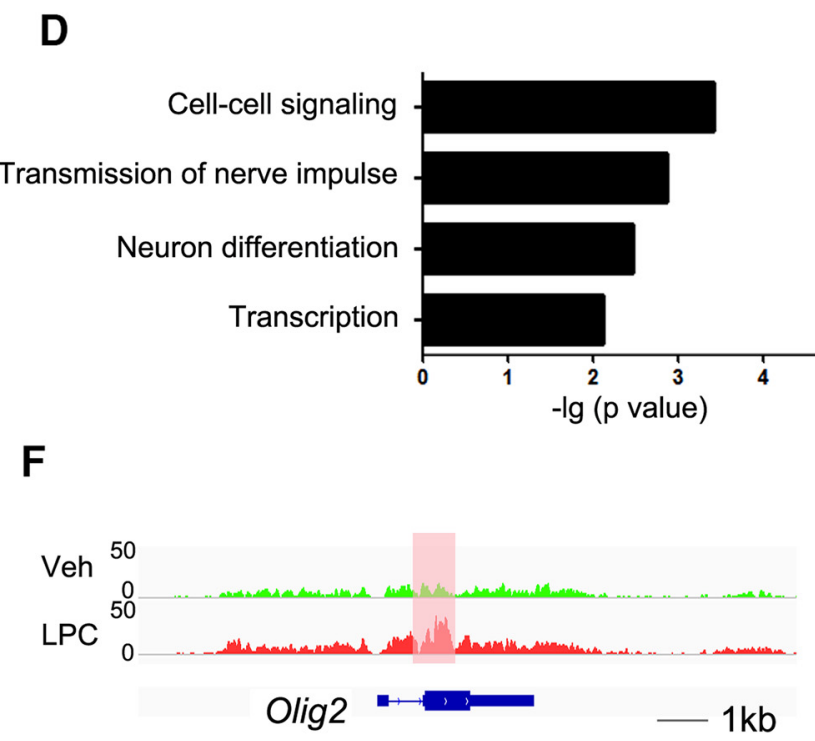

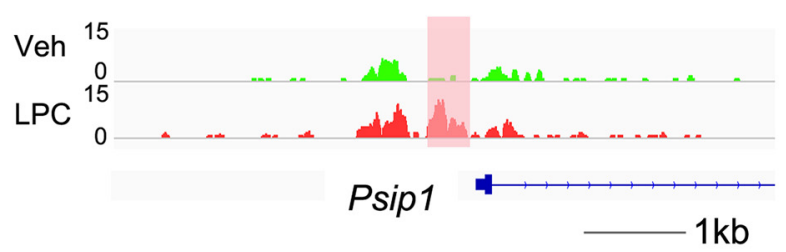

E

\begin{tabular}{|c|c|c|}
\hline Gene & $\begin{array}{c}\text { Tags } \\
\text { (after LPC treatment) }\end{array}$ & $\begin{array}{c}\text { Fold Change } \\
\text { (Treated / Untreated) }\end{array}$ \\
\hline Olig2 & 1689 & 2.45 \\
\hline Gmeb2 & 194 & 3.13 \\
\hline Psip1 & 141 & 4.85 \\
\hline Smad7 & 127 & 4.13 \\
\hline Polr2h & 60 & 3.68 \\
Eif2C2 & 55 & 5.1 \\
KIf6 & 34 & 4.88 \\
\hline Nab1 & 32 & 13.83 \\
\hline
\end{tabular}
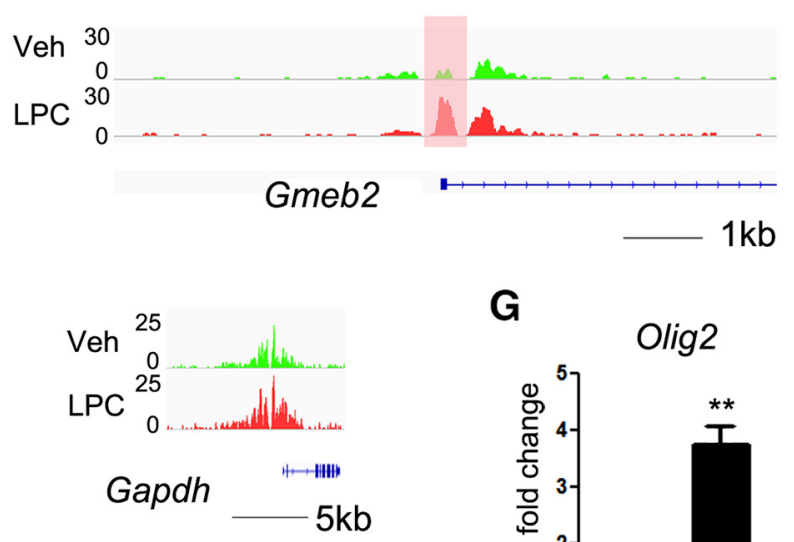

G

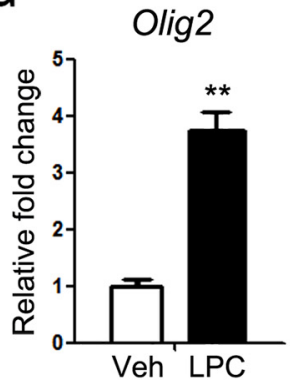

Figure 1. Olig2 is an important transcription factor in LPC-injured oligodendrocytes. A, Schematic overview of oligodendrocyte (OL) sample preparation for Chip-Seq analysis. Mature oligodendrocytes were cultured and treated with LPC for $12 \mathrm{~h}$ before chromatin immunoprecipitation. $\boldsymbol{B}$, Heat maps of the H3K27Acsignals in the vehicle-treated and LPC-treated oligodendrocytes. Each line on the $y$-axis represents a genomic region of $\pm 2.5 \mathrm{~kb}$ flanking the H3K27Ac peaks. C, Genomic distribution of the H3K27Ac peaks in vehicle-treated and LPC-treated oligodendrocytes. TSS, Transcription start site; TTS, transcription termination site. $\boldsymbol{D}, \mathrm{GO}$ analysis of the differentially H3K27Ac-bound genes. $\boldsymbol{E}$, The transcription factors with the most significant differential in intensity of H3K27Ac-bound peaks as determined by the tag numbers with and without LPC treatment. $\boldsymbol{F}$, Genome browser view of the distribution of H3K27Ac on Olig2, Gmeb2, Psip1, and Gapdh. G, Quantitative real-time PCR analysis of the Olig2 mRNA levels in vehicle oligodendrocytes and oligodendrocytes treated with $12.5 \mathrm{~mm} L \mathrm{PC}$ for $12 \mathrm{~h}$. Data represent the means \pm SEM from three independent experiments. ${ }^{* *} p<0.01$, Student's $t$ test. Veh, Vehicle.

Cell viability and intracellular cAMP concentration assessment. To assess cell viability, primary rat OPCs were cultured in poly-D-lysine (Sigma)-coated wells of 96 -well plates at a density of $1 \times 10^{4} /$ well and treated with ligands of interest for $48 \mathrm{~h}$ before assessment. Cell viability was assessed using the Cell Counting Kit-8 (Donjino) according to the manufacturer's instructions.
To assess intracellular cAMP concentration, primary rat OPCs were cultured in poly-D-lysine (Sigma)-coated wells of 96-well plates at a density of $1 \times 10^{4} /$ well and treated with pranlukast at the indicated concentration and $1 \mathrm{~mm}$ forskolin (Sigma) for $5 \mathrm{~min}$. cAMP was quantified using the cAMPGlo Assay kit (Promega) following the manufacturer's instructions. 


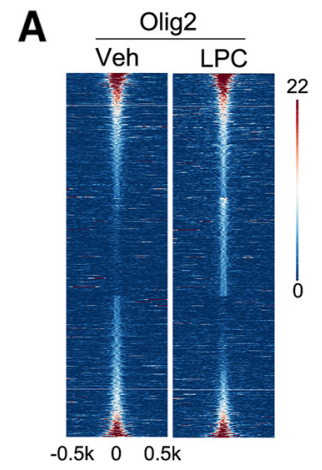

B

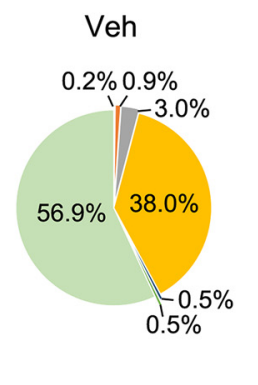

C

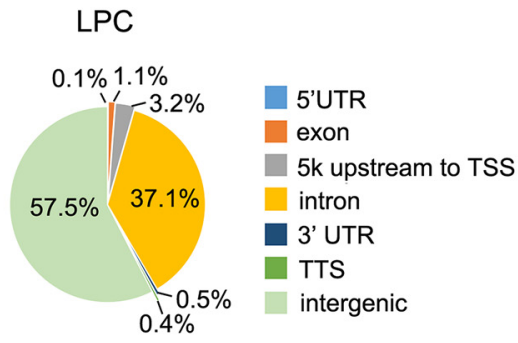

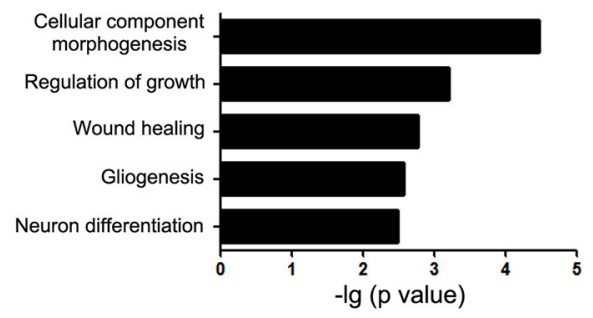

D

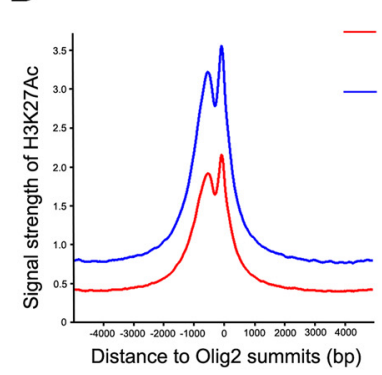

$\mathbf{F}$

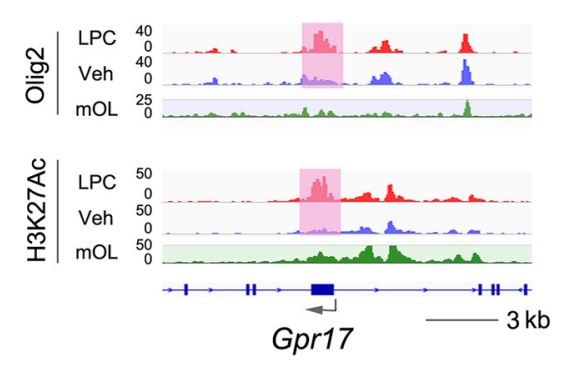

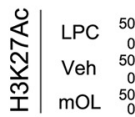

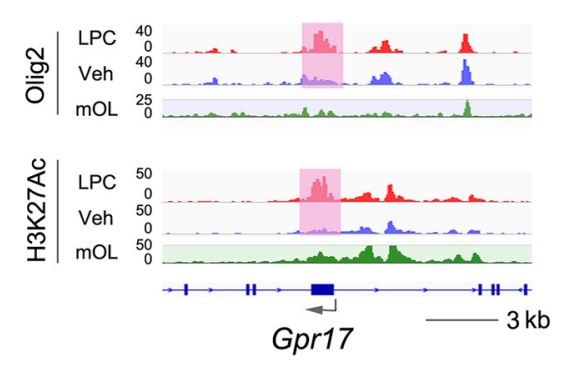

$\mathbf{E}$

\begin{tabular}{|c|c|c|}
\hline Gene & $\begin{array}{c}\text { Tags } \\
\text { (after LPC treatment) }\end{array}$ & $\begin{array}{c}\text { Fold Change } \\
\text { (Treated / Untreated) }\end{array}$ \\
\hline Gpr17 & 339 & 3.46 \\
\hline Olig2 & 230 & 2.81 \\
\hline Nfix & 48 & 8.12 \\
\hline Wrt7b & 33 & 13.79 \\
\hline Ndufs4 & 32 & 0.05 \\
\hline Fggy & 28 & 0.09 \\
\hline Vrk3 & 27 & 7.75 \\
\hline Bcat1 & 24 & 11.38 \\
\hline
\end{tabular}

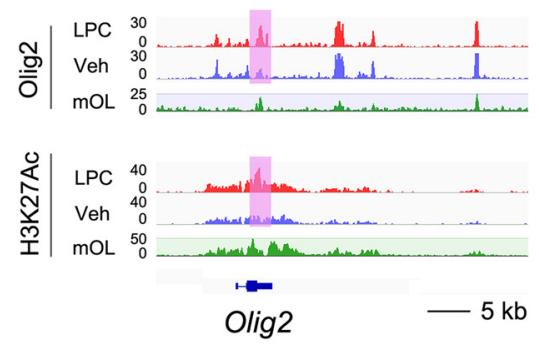

G

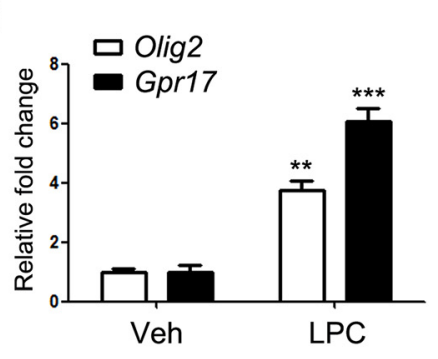

Figure 2. Gpr17 is a transcriptional target of Olig2 in LPC-treated oligodendrocytes. $\boldsymbol{A}$, Heat maps of the Olig2-binding signals in oligodendrocytes treated with vehicle (Veh) or LPC. Each line on the $y$-axis represents a genomic region of $\pm 0.5 \mathrm{~kb}$ flanking the 0 lig2 peaks. $\boldsymbol{B}$, Genomic distributions of the 0 lig2 peaks in oligodendrocytes treated with vehicle or LPC. TSS, Transcription start site; TTS, transcription termination site. $\boldsymbol{C}, \mathrm{GO}$ analysis of the differentially Olig2-bound genes. $\boldsymbol{D}$, Binding profiles of H3K27Ac around 0 lig2 summits in oligodendrocytes treated with vehicle or LPC. $\boldsymbol{E}$, Top-ranking genes with differentially Olig2-bound peaks as determined by the Tags. $\boldsymbol{F}$, Genome browser view of the distributions of Olig2 and H3K27Ac on Gpr 17 and Olig2. G, Quantitative real-time PCR analysis of the Gpr17 and Olig2 mRNA levels in oligodendrocytes treated with vehicle or $12.5 \mathrm{~mm} \mathrm{LPC} \mathrm{for} 12 \mathrm{~h}$. Data are means \pm SEM from three independent experiments. ${ }^{* *} p<0.01,{ }^{* * *} p$ $<0.001$, Student's $t$ test. Veh, Vehicle.

Electron microscopy. The corpus callosum regions from 8-week-old wild-type or $G \operatorname{pr} 17^{-1-}$ mice were dissected and fixed in a solution of $2 \%$ paraformaldehyde, $2 \%$ glutaraldehyde (v/v), and $0.1 \mathrm{~m}$ cacodylic acid, $\mathrm{pH}$ 7.2, and processed for electron microscopy as described previously (Chen et al., 2009).

Statistical analysis. The data for two-group comparisons were analyzed for statistical significance using two-tailed Student's $t$ tests. Error bars represent SEM. Values of $p<0.05$ were considered significant. For multiple comparisons, which were performed using one-way ANOVAs, the Tukey's multiple-comparison test was used for post-tests.

\section{Results}

Genome-wide mapping of activating histone marks in LPC-treated oligodendrocytes

LPC treatment elicits demyelination and mimics the effects of demyelinating disease in the CNS (Franklin, 2002). Recent reports, however, indicate that LPC is also toxic to oligodendrocytes (Fressinaud, 2005; Fressinaud and Eyer, 2014), suggesting that demyelination caused by LPC in vivo is, in part, attributable to oligodendrocyte cell death, although the molecular basis remains unclear.
To investigate the transcriptional alterations in oligodendrocytes treated with LPC, ChIP-Seq mapping of histone 3 acetylated at lysine 27 (H3K27Ac) was performed in cultured oligodendrocytes treated with LPC (Fig. 1A). H3K27Ac marks actively transcribed regions (Heintzman et al., 2009; Creyghton et al., 2010; Rada-Iglesias et al., 2011). Primary rat OPCs were cultured in differentiation medium for $4 \mathrm{~d}$. After $4 \mathrm{~d}$, the cells were fully mature oligodendrocytes, and $M b p$ expression had increased $>150$-fold over that in OPCs. The cells were subjected to LPC treatment and analyzed by H3K27Ac ChIP-Seq analysis. Since prolonged LPC treatment can result in significant oligodendrocyte death, we treated cells for $12 \mathrm{~h}$. After $12 \mathrm{~h}$ in the presence of LPC, the cells were viable (data not shown). We analyzed the difference in recruitment of $\mathrm{H} 3 \mathrm{~K} 27 \mathrm{Ac}$ in oligodendrocytes with and without LPC treatment. In cells treated with LPC, the overall recruitment of $\mathrm{H} 3 \mathrm{~K} 27 \mathrm{Ac}$ to $5^{\prime} \mathrm{UTR}$ and exon regions was moderately higher than in vehicle-treated cells: from $1.7 \%$ to $2.2 \%$ and from $2.5 \%$ to $3.1 \%$ in $5^{\prime}$ UTRs and exons, respectively (Fig. $1 B, C$ ). 


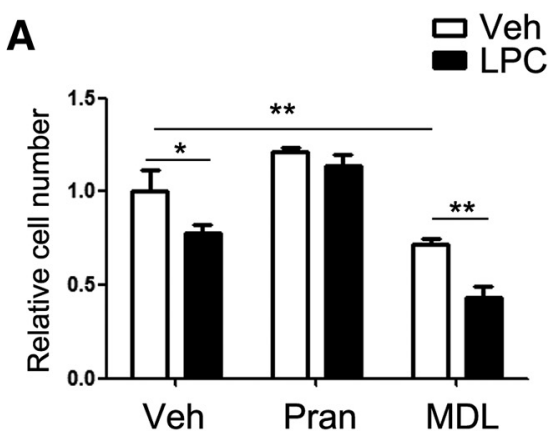

C

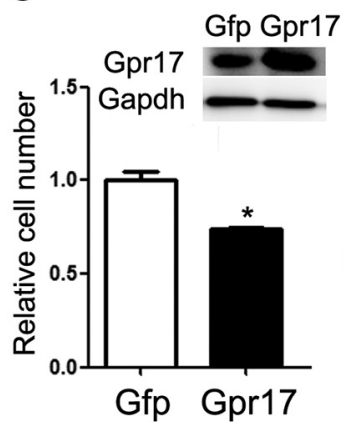

B

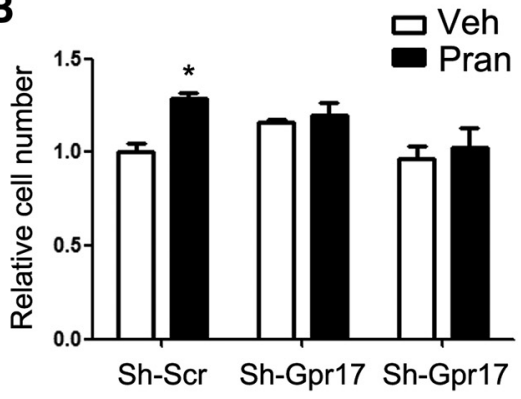

(I)

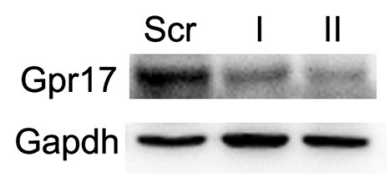

E

D

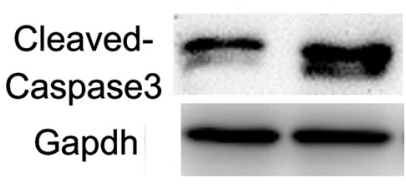

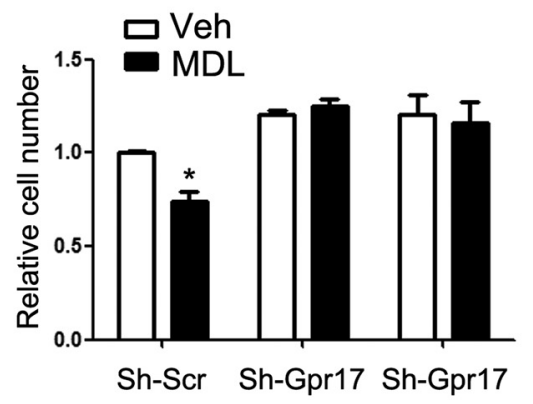

(I)

(II)

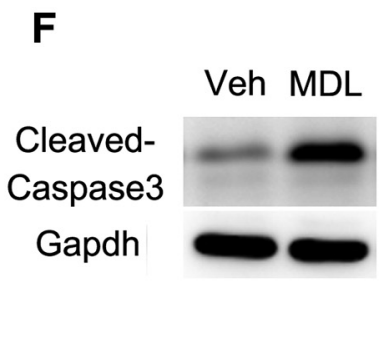

Figure 3. Gpr17 regulates oligodendrocyte survival by controlling Xaf1 expression. A, Relative numbers of viable oligodendrocytes after treatment with vehicle or $12.5 \mathrm{~mm} L \mathrm{LC}$ for $24 \mathrm{~h}$. The oligodendrocytes were treated with $10 \mathrm{~mm}$ pranlukast or $10 \mathrm{~nm} \mathrm{MDL} 29951$ for $24 \mathrm{~h}$ before LPC treatment. Data are means \pm SEM from three independent experiments. ${ }^{*} p<0.05,{ }^{* *} p<0.01$, two-way ANOVA. B, Relative numbers of viable OPCs treated with indicated shRNAs and $10 \mathrm{~mm}$ pranlukast for $48 \mathrm{~h}$. The effect on Gpr17 levels was confirmed by Western blot analysis. Data are means \pm SEM from three independent experiments. ${ }^{*} p<0.05$, two-way ANOVA. C, Relative numbers of viable OPCs overexpressing Gpr17 or transfected with control vector (Gfp) for $48 \mathrm{~h}$. Overexpression of Gpr17 was confirmed by Western blot analysis. Data are means \pm SEM from three independent experiments. ${ }^{*} p<0.05$, Student's $t$ test. D, Primary rat OPCs were transfected with control Gfp and Gpr17-expressing vectors and cultured in the differentiation medium for $48 \mathrm{~h}$. Cleaved caspase 3 was assessed by Western blot analysis. E, Relative numbers of viable OPCs treated with indicated shRNAs (shScr indicates scrambled control) and $10 \mathrm{~nm} \mathrm{MDL} 29951$ for $48 \mathrm{~h}$. Data are means \pm SEM from three independent experiments. ${ }^{*} p<0.05$, two-way ANOVA. F, Western blot analysis of cleaved caspase 3 in oligodendrocytes treated with $10 \mathrm{~nm}$ MDL29951 in the differentiation medium for $48 \mathrm{~h}$. Veh, Vehicle; Pran, pranlukast; MDL, MDL29951; shScr, scrambled control.

Based on Gene Ontology (GO) analysis, the genes that exhibited differential H3K27Ac recruitment were categorized into biological processes that included cell-cell signaling, transmission of nerve impulse, neuron differentiation, and transcription (Fig. $1 D)$. We were particularly interested in the transcription factors that might regulate these processes in oligodendrocytes after LPC treatment. Among the differentially H3K27Ac-bound genes were those encoding $>20$ transcription factors, including Olig2, Gmeb2, Psip1, Smad7, Klf6, and Nab1 (Fig. 1E,F). Of these, Olig2, which encodes a bHLH transcription factor known to be critical for oligodendrocyte specification and differentiation (Lu et al., 2002; Zhou and Anderson, 2002; Yue et al., 2006), was among the genes with the most significantly different $\mathrm{H} 3 \mathrm{~K} 27 \mathrm{Ac}$ recruitment in LPC-treated and vehicletreated cells (Fig. 1E,F). Consistent with the H3K27Ac enrichment, expression of Olig2 was upregulated after LPC treatment as shown by qRT-PCR analysis (Fig. 1G).

Gpr17 is targeted by Olig2 and is a potential regulator of oligodendrocyte survival

To identify the downstream targets of Olig2 in LPC-treated oligodendrocytes, we performed Olig2 ChIP-Seq analysis of oligodendrocytes with and without LPC treatment. The distribution of Olig2 genome occupancy and the intensity of Olig2-bound peaks were altered in oligodendrocytes in response to LPC treatment (Fig. 2A,B). GO analysis revealed that the Olig2-targeted genes in LPC-treated oligodendrocytes were involved in biologi- cal processes related to cellular component morphogenesis, regulation of growth, wound healing, gliogenesis, and neuron differentiation (Fig. 2C). Furthermore, overlapping analysis of co-occupancy showed that intensities of H3K27Ac peaks on Olig2-binding sites in oligodendrocytes were higher after LPC treatment than in vehicle-treated cells (Fig. 2D).

Gpr17 was among the genes with the largest increase in Olig2 binding when LPC and vehicle treatments were compared (Fig. 2E). Gpr17 was previously identified as a cell-intrinsic factor that regulates oligodendrocyte differentiation and myelination (Chen et al., 2009). Our data indicate that Olig2 targets the Gpr17 locus and that Olig2 occupancy increases in oligodendrocytes after LPC treatment.

Co-occupancy of Olig2 and the activating histone mark $\mathrm{H} 3 \mathrm{~K} 27 \mathrm{Ac}$ is likely indicative of transcriptional activation in oligodendrocytes in response to LPC. Intriguingly, Olig2 and H3K27Ac co-occupancy was enhanced on the exons of Olig2 and Gpr17 in oligodendrocytes after LPC treatment (Fig. $2 F$ ), although Olig2 recruitment to Gpr17 and Olig2 promoter regions was not substantially altered (Fig. $2 F$ ). Recent studies indicate that protein-coding exons frequently contain enhancers that function at the transcriptional level (Birnbaum et al., 2012; Ritter et al., 2012). The Olig2 and H3K27Ac patterns on the Gpr17 and Olig2 loci in the absence of LPC treatment were essentially identical to those previously published (Yu Y et al., 2013). In LPCtreated oligodendrocytes, the increased Olig2 and H3K27Ac binding was associated with upregulation of Gpr17 and Olig2 
A

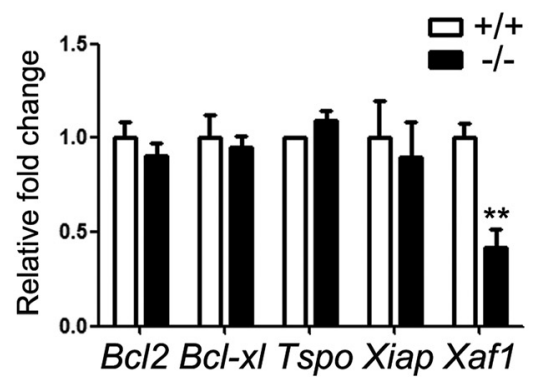

D

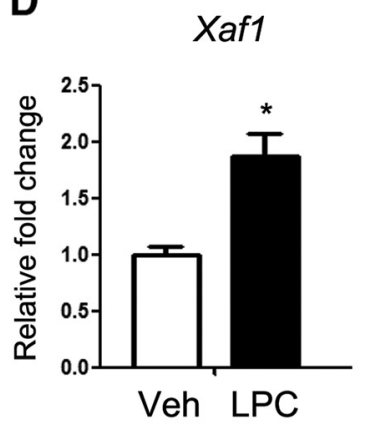

H

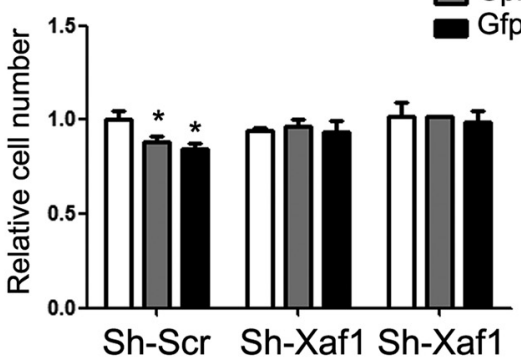

(I)

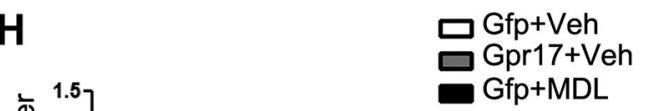

(II)
E

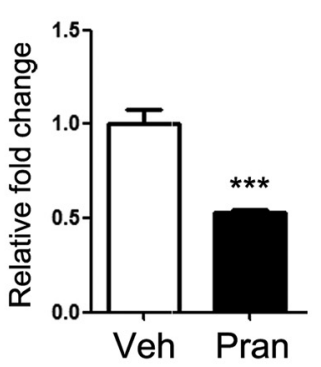

B

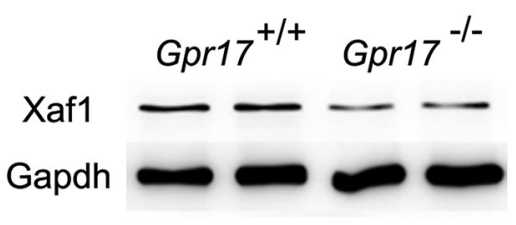

C

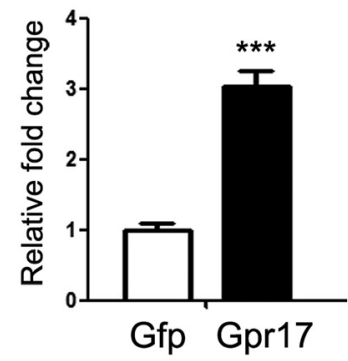

$\mathbf{F}$

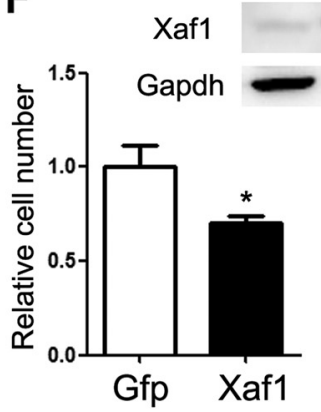

G

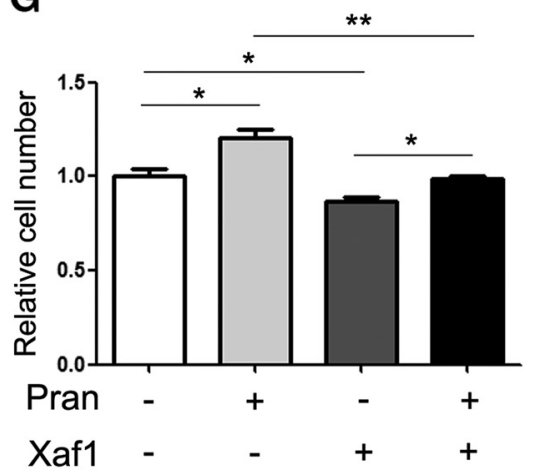

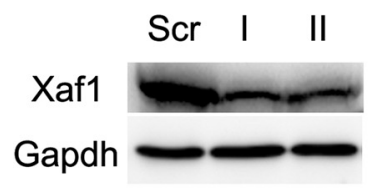

Gapdh
I

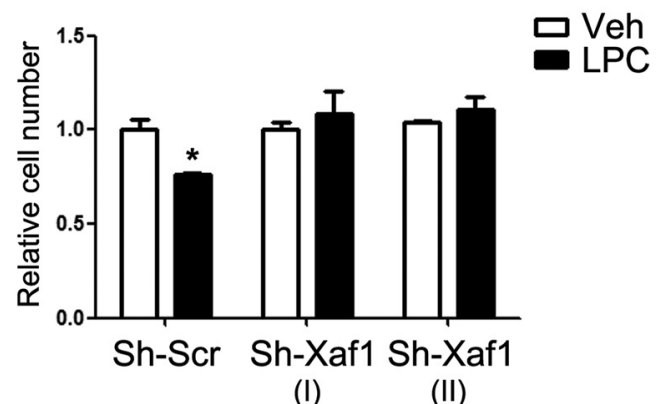

Figure 4. Xaf1 is essential for Gpr17-mediated regulation of oligodendrocyte apoptosis. $A$, Expression of apoptosis-related genes in the total RNA from whole brains of control $(+/+)$ and Gpr $17^{-1-}$ mice at 8 weeks of age ( $n=8$ animals per genotype). ${ }^{* *} p<0.01$, Student's $t$ test. $B$, Western blot analysis of control and Gpr $17^{-I-}$ mice for Xaf1 ( $n=6$ animals per genotype). C, Expression of Xaf1 in the total RNA from oligodendrocytes overexpressing Gpr17 or transfected with control vector (Gfp). Primary rat OPCs were transfected and cultured in the differentiation medium for $48 \mathrm{~h}$. Data are means \pm SEM from three independent experiments. ${ }^{* * *} p<0.001$, Student's $t$ test. $D$, Expression of the Xaf1 mRNA level in mature oligodendrocytes treated with vehicle or $12.5 \mathrm{~mm}$ LPC for $24 \mathrm{~h}$. Data are means \pm SEM from three independent experiments. ${ }^{*} p<0.05$, Student's $t$ test. $\boldsymbol{E}$, Expression of Xaf1 in the total RNA from oligodendrocytes treated with vehicles or 10 mm pranlukast in the differentiation medium for $48 \mathrm{~h}$. Data are means \pm SEM from three independent experiments. ${ }^{* * *} p<0.001$, Student's $t$ test. $\boldsymbol{F}$, Relative numbers of viable OPCs overexpressing Xaf1 or transfected with control vector (Gfp) for $48 \mathrm{~h}$. The level of Xaf1 was confirmed by Western blot analysis. Data are means \pm SEM from three independent experiments. ${ }^{*} p<0.05$, Student's $t$ test. G, Relative numbers of viable OPCs overexpressing Xaf1 or transfected with control vector (Gfp) and treated with $10 \mu \mathrm{m}$ pranlukast for $48 \mathrm{~h}$. Data are means \pm SEM from three independent experiments. ${ }^{*} p<0.05,{ }^{* *} p<0.01$, one-way ANOVA with Tukey's multiple-comparison test. $\boldsymbol{H}$, Relative numbers of viable OPCs treated with control vector and vehicle (Gfp +Veh), overexpressing Gpr17 and treated with vehicle (Gpr17+Veh), or treated with control vector and $10 \mathrm{~nm}$ MDL29951 and with the indicated shRNA for $48 \mathrm{~h}$. The inhibition of Xaf1 expression was confirmed by Western blot analysis. Data are means \pm SEM from three independent experiments. ${ }^{*} p<0.05$, two-way ANOVA. I, Relative numbers of viable OPCs treated with $12.5 \mathrm{~mm} \mathrm{LPC}$ and indicated shRNA for $48 \mathrm{~h}$. Data are means \pm SEM from three independent experiments. ${ }^{*} p<0.05$, tw0-way ANOVA. Veh, Vehicle; Pran, pranlukast; MDL, MDL29951; shScr, scrambled control.

expression (Fig. 2G), suggesting that Olig2 recruitment to exons of Olig2 and Gpr17 enhances their expression.

\section{The role of Gpr17 in oligodendrocyte survival}

The upregulation of Gpr17 expression during LPC treatment indicated its potential role in oligodendrocyte survival. Gpr17 inhibitor pranlukast ameliorated the deleterious effect of LPC on cell viability, whereas the Gpr17 agonist MDL29951 (Hennen et al., 2013) augmented the effect of LPC (Fig. 3A). Gpr17 silencing by treatment of cells with a lentiviral shRNA diminished the protective effect of pranlukast on cell viability (Fig. $3 B$ ). In contrast, overexpression (Fig. 3C,D) or activation (Fig. 3E,F) of Gpr17 with MDL29951 reduced the viable oligodendrocyte population by inducing cell apoptosis, as indicated by the increased protein level of cleaved caspase 3 . As reported previously in experiments with Gpr17 $17^{-1-}$ primary oligodendrocytes (Hennen et al., 2013), treatment of cells with an shRNA targeting Gpr17 likewise abolished the effects of pranlukast and MDL29951 on oligodendrocyte viability (Fig. $3 B, E$ ), confirming the specificities of these compounds for Gpr17.

To investigate the effect of Gpr17 on oligodendrocyte apoptosis, we examined expression of cell death-related genes in control 
A

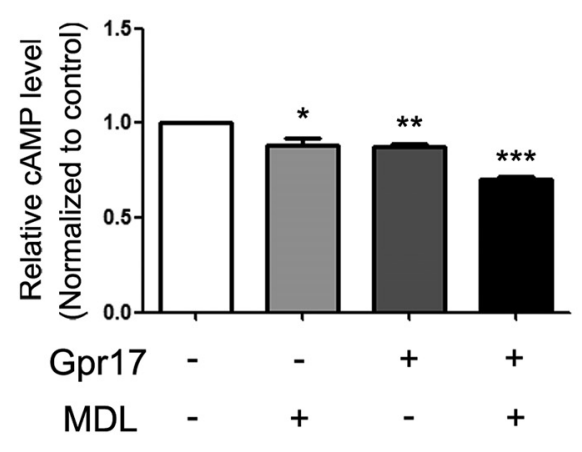

B

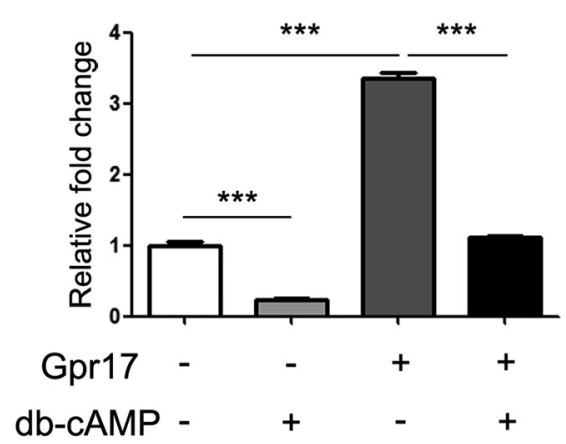

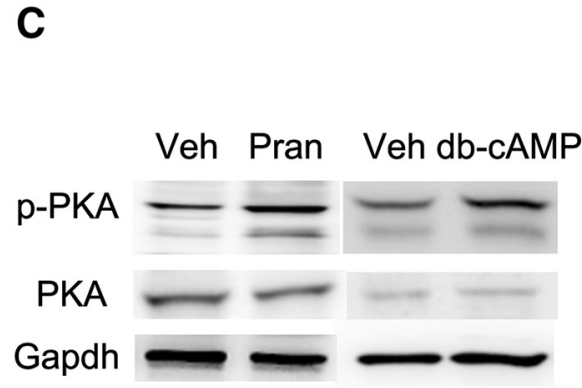

D
E

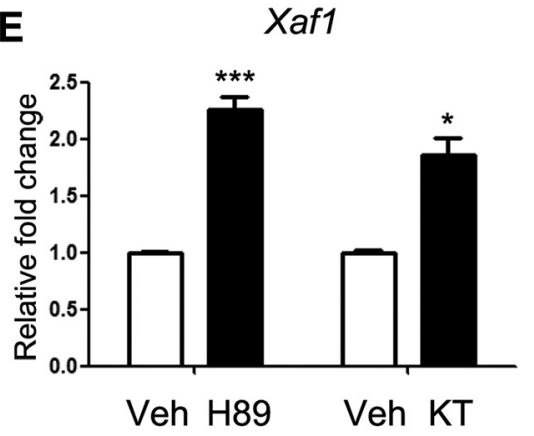

Figure 5. Gpr17 regulates oligodendrocyte apoptosis and Xaf1 expression through the CAMP and PKA signaling pathways. $A$, Relative cAMP levels in cultured OPCs overexpressing Gpr17 or transfected with control vector for $48 \mathrm{~h}$ and treated with $10 \mathrm{~nm} \mathrm{MDL} 29951$ or vehicle for 5 min as indicated. ${ }^{*} p<0.05,{ }^{* *} p<0.01,{ }^{* * *} p<0.001,0$ ne-way ANOVA with Tukey's multiple-comparison test. $\boldsymbol{B}$, Expression of Xaf1 in total RNA from oligodendrocytes overexpressing Gpr17 or transfected with control vector. Primary rat OPCS were transfected and treated with 0.5 mm dibutyryl cAMP or vehicle as indicated in the differentiation medium for $48 \mathrm{~h}$. Data are means \pm SEM from three independent experiments. ${ }^{* * *} p<0.001$, one-way ANOVA with Tukey's multiple-comparison test. C, Western blot analyses of phosphorylated PKA in oligodendrocytes treated with vehicle DMSO, $10 \mu$ m pranlukast, or 0.5 mm dibutyryl cAMP in the differentiation medium for $48 \mathrm{~h}$. $\boldsymbol{D}$, Relative numbers of viable OPCs treated with vehicle or $10 \mu$ m pranlukast and the indicated concentration of H 89 for $48 \mathrm{~h}$. Data are means \pm SEM from three independent experiments. ${ }^{* *} p<0.01,{ }^{* * *} p<$ 0.001 , one-way ANOVA with Tukey's multiple-comparison test. $\boldsymbol{E}$, Expression of Xaf1 in the total RNA from oligodendrocytes treated with $10 \mu \mathrm{m}$ H89 or 0.5 mm KT5720 in the differentiation medium for $48 \mathrm{~h}$. Data are means \pm SEM from three independent experiments. ${ }^{*} p<0.05,{ }^{* * *} p<0.001$, Student's $t$ test. Veh, Vehicle; Pran, pranlukast; MDL, MDL29951; db-cAMP, dibutyryl cAMP; KT, KT5720.

and Gpr17-null oligodendrocytes. We found that Xaf1 (XIAPassociated factor 1), a well characterized tumor suppressor that leads to apoptosis in different types of cells (Byun et al., 2003; Zhang et al., 2010; Sun et al., 2011; Zou et al., 2012; Zhu et al., 2014), was downregulated in $G$ pr17 $7^{-1-}$ mice relative to levels in control mice (Fig. $4 A, B$ ). In contrast, overexpression of Gpr17 in oligodendrocytes in vitro increased the expression of Xaf1 (Fig. $4 C$ ). These observations suggest that activation of Gpr17 enhances Xaf1-mediated cell death signaling.

LPC treatment of cultured oligodendrocytes induced Xaf1 expression (Fig. 4D). Conversely, inhibition of Gpr17 activity with pranlukast in oligodendrocytes reduced the expression of Xaf1 (Fig. 4E). Furthermore, overexpression of Xaf1 reduced cell viability (Fig. $4 F$ ) and antagonized the protective effect of pranlukast in oligodendrocytes (Fig. $4 G$ ). In contrast, the treatment of cells with an shRNA that resulted in reduction of endogenous Xaf1 expression reversed the apoptotic effects of both Gpr17 overexpression and of MDL29951 treatment (Fig. 4H). Moreover, silencing of Xaf1 blunted the deleterious effect of LPC on oligodendrocytes (Fig. 4I). These data suggest that Xaf1 is a downstream mediator of Gpr17 in LPC-induced oligodendrocyte apoptosis.

Gpr17 regulates oligodendrocyte survival through the PKA signaling pathway

To elucidate the molecular basis of the regulation of Xaf1 by Gpr17, we investigated the downstream molecules associated with Gpr17. Previous studies indicated that activated Gpr17 coupled with the G $\alpha$ i subunit decreased the intracellular cAMP concentration (Ciana et al., 2006). In oligodendrocytes, the activation of Gpr17 with MDL29951 resulted in a decreased intracellular cAMP concentration relative to vehicle-treated control cells (Fig. 5A). Like pranlukast treatment, cAMP supplementation (dibutyryl cAMP) effectively reduced Xaf1 mRNA levels (Fig. $5 B)$. Moreover, cAMP antagonized the induction of Xaf1 expression caused by Gpr17 overexpression in oligodendrocytes (Fig. $5 B$ ), suggesting that cAMP mediates the biological effects of Gpr17 on oligodendrocyte survival.

In oligodendrocytes, the PKA signaling pathway is involved in cell differentiation through the regulation of its downstream effectors CREB and Epac1 (Simon et al., 2016). The administration of cAMP to oligodendrocytes promoted the phosphorylation of PKA, and the inhibition of Gpr17 with pranlukast resulted in comparable PKA activation (Fig. 5C). The inhibition of PKA signaling with PKA inhibitor H89 reduced cell viability observed after pranlukast treatment (Fig. 5D) and increased Xaf1 expression (Fig. 5E). Similarly, treatment of oligodendrocytes with another PKA pathway inhibitor, KT5720, resulted in elevation of Xaf1 expression (Fig. 5E).

c-Fos, a downstream proto-oncogene in the PKA signaling pathway (Boutillier et al., 1992; Tyson et al., 1999), is a regulator of cell survival (Suda et al., 2014). The overexpression of Gpr17 reduced the expression of c-Fos in oligodendrocytes (Fig. 6A). In contrast, activation of PKA signaling by treatment of cells with 
A

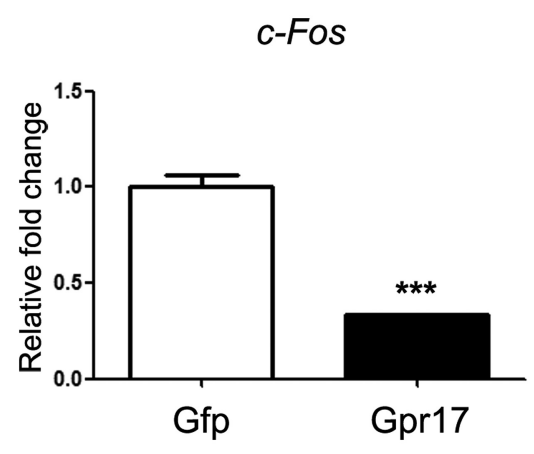

D

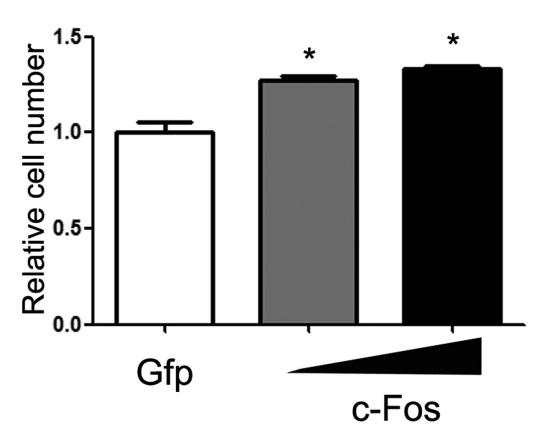

B

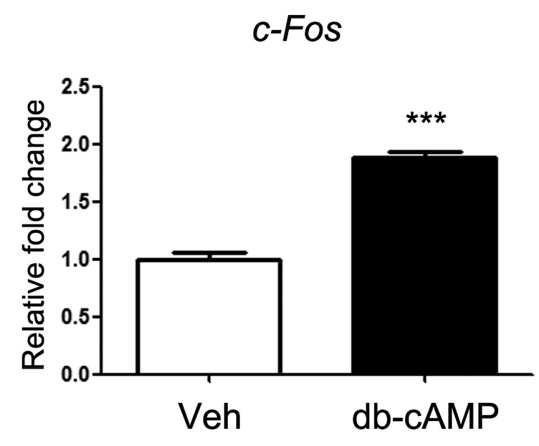

E

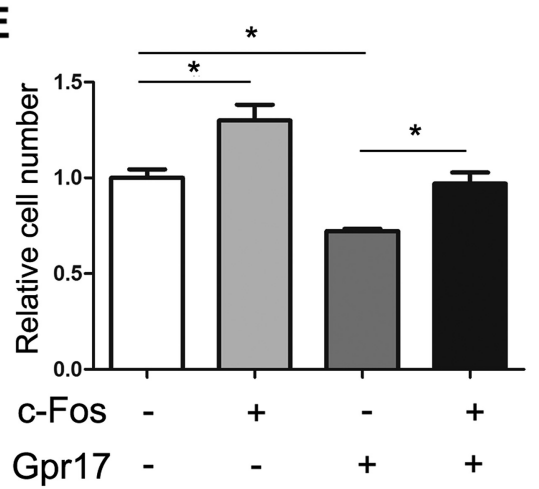

C

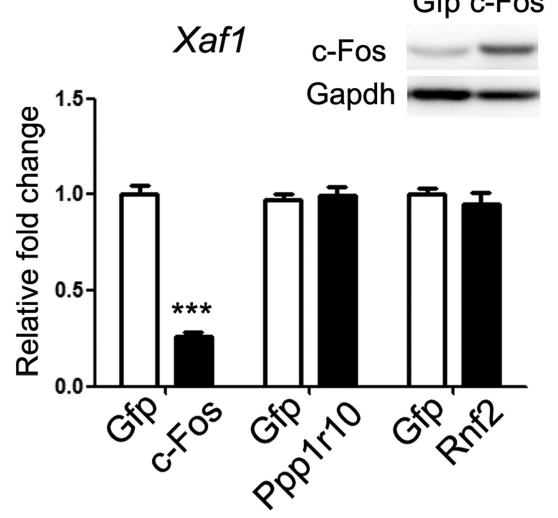

$\mathbf{F}$

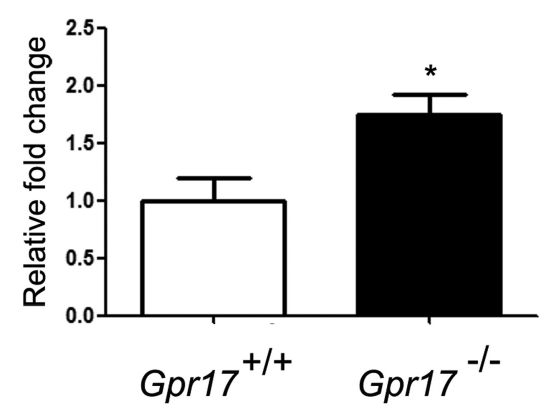

Figure 6. c-Fos mediates the effects of Gpr17 on oligodendrocyte survival. $A$, Expression of c-Fos in the total RNA from oligodendrocytes overexpressing Gpr17 compared with expression in cells transfected with vector control. Primary rat $\mathrm{OPCs}$ were transfected and cultured in the differentiation medium for $48 \mathrm{~h}$. Data are means $\pm S E M$ from three independent experiments. ${ }^{* * *} p<0.001$, Student's $t$ test. $\boldsymbol{B}$, Expression of c-Fos in the total RNA from oligodendrocytes treated with $0.5 \mathrm{~mm}$ dibutyryl cAMP (db-cAMP) in the differentiation medium for $48 \mathrm{~h}$. Data are means \pm SEM from three independent experiments. ${ }^{* * *} p<0.001$, Student's t test. C, Expression of Xaf1 in the total RNA from oligodendrocytes overexpressing c-Fos, Ppp1r10, or Rnf2 or transfected with vector (Gfp). Primary rat $\mathrm{OPC} s$ were transfected and cultured in the differentiation medium for $48 \mathrm{~h}$. The level of c-Fos was analyzed by Western blot. Data are means \pm SEM from three independent experiments. ${ }^{* * *} p<0.001$, Student's $t$ test. $\boldsymbol{D}$, Relative numbers of viable OPCs overexpressing c-Fos at two concentrations for $48 \mathrm{~h}$. Data are means \pm SEM from three independent experiments. ${ }^{*} p<0.05$, one-way ANOVA with Tukey's multiple-comparison test. $\boldsymbol{E}$, Relative numbers of viable OPCs overexpressing Gpr17 and/or c-Fos compared with cells transfected with vector control for $48 \mathrm{~h}$. Data are means \pm SEM from three independent experiments. ${ }^{*} p<0.05$, one-way ANOVA with Tukey's multiple-comparison test. $\boldsymbol{F}$, Expression of c-Fos in the total RNA from the forebrains of Gpr $17^{+/+}$ and $G$ pr $17^{-1-}$ mice at 8 weeks of age ( $n=8$ animals per genotype). ${ }^{*} p<0.05$, Student's $t$ test.

dibutyryl cAMP increased the expression of c-Fos (Fig. 6B). Overexpression of c-Fos, but not regulatory factors Rnf2 or Ppp1r10, significantly suppressed Xaf1 expression (Fig. 6C). Furthermore, the elevation of c-Fos levels increased oligodendrocyte viability (Fig. 6D) and rescued the reduction in viability caused by Gpr17 overexpression (Fig. 6E). In Gpr17 $17^{-1-}$ mice, the level of c-Fos was greater than that in their wild-type littermates (Fig. $6 F$ ), supporting observations obtained from the in vitro experiments. Together, our data suggest that Gpr17 activation results in a decrease in intracellular cAMP levels, suppresses the activation of the PKA signaling pathway, and results in reduced expression of c-Fos and upregulation of Xaf1, leading to oligodendrocyte apoptosis.

\section{Gpr17 activation blocks oligodendrocyte maturation via inhibition of Epac1}

We found that overexpression of Gpr17 in primary rat OPCs inhibited differentiation (Fig. 7A), whereas inhibition of Gpr17 activity with pranlukast or cAMP supplementation promoted differentiation (Fig. 7B). Consistent with a recent report (Simon et al., 2016), we found that the loss of Gpr17 promoted OPC differentiation by elevation of Epac1. Accordingly, the inhibition of Epac1 activity by ESI-09 reduced oligodendrocyte maturation (Fig. 7C,D). Overexpression of Gpr17 in cultured OPCs reduced the level of intracellular Epac1 (Fig. 7E), whereas the loss of Gpr17 in mice resulted in elevated Epac1 expression (Fig. $7 F$ ). Inhibition of Gpr17 activity with pranlukast or cAMP supplementation induced Epac1 expression in oligodendrocytes (Fig. 7G). Moreover, overexpression of Epac1 in OPCs blocked the inhibitory effect of Gpr17 overexpression on cell differentiation (Fig. $7 H$ ). Gpr17 did not have a significant effect on OPC proliferation because the overexpression or inhibition of Gpr17 did not affect the Ki67- or BrdU-positive cell populations of OPCs (data not shown).

Loss of Gpr17 promotes remyelination after drug-induced demyelination in the CNS

Our in vitro finding that the inhibition of Gpr17 activity reduced oligodendrocyte apoptosis led us to hypothesize that loss of the Gpr17 gene in vivo would be beneficial to myelination. Previously, analysis of Gpr17-null mice showed that Gpr17 functioned as a cell-intrinsic factor that blocked oligodendrocyte terminal differentiation (Chen et al., 2009). Given the potential expression of Gpr17 in other cell types (Ceruti et al., 2009; Franke et al., 2013), Gpr17 deletion in mice may have affected other cell lineage development. We then generated a conditional mutant carrying Gpr17 floxed (fl) alleles by homologous recombination in embryonic stem cells to investigate the cell-autonomous function of Gpr17 in oligodendrocyte myelination. The Gpr $17^{\text {fl/fl }}$ mouse line 
A

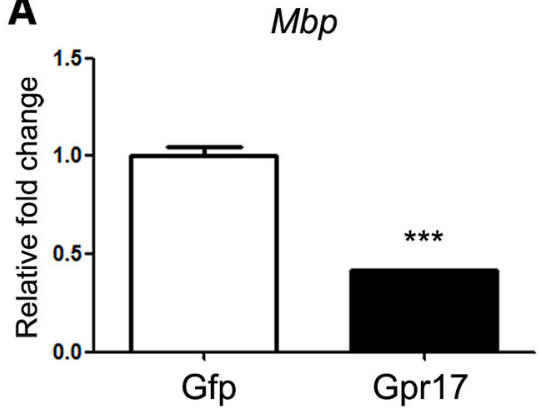

D

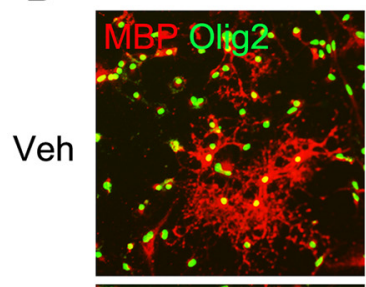

Veh

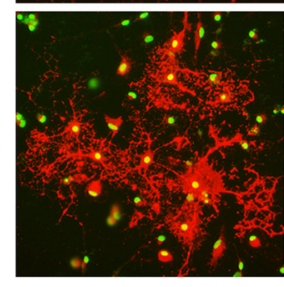

G

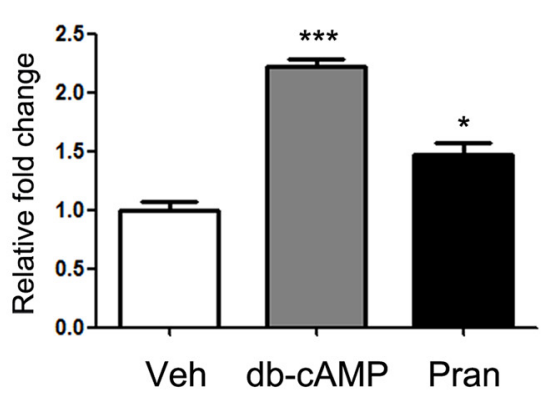

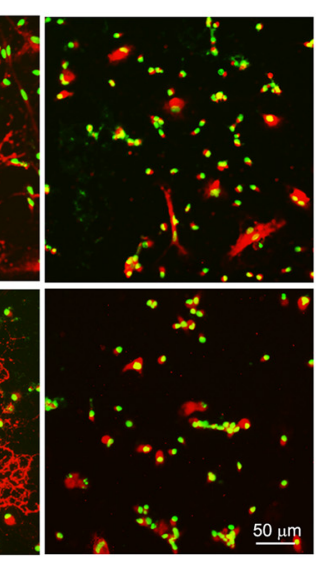

E

H

Epac1

H

Vec
B
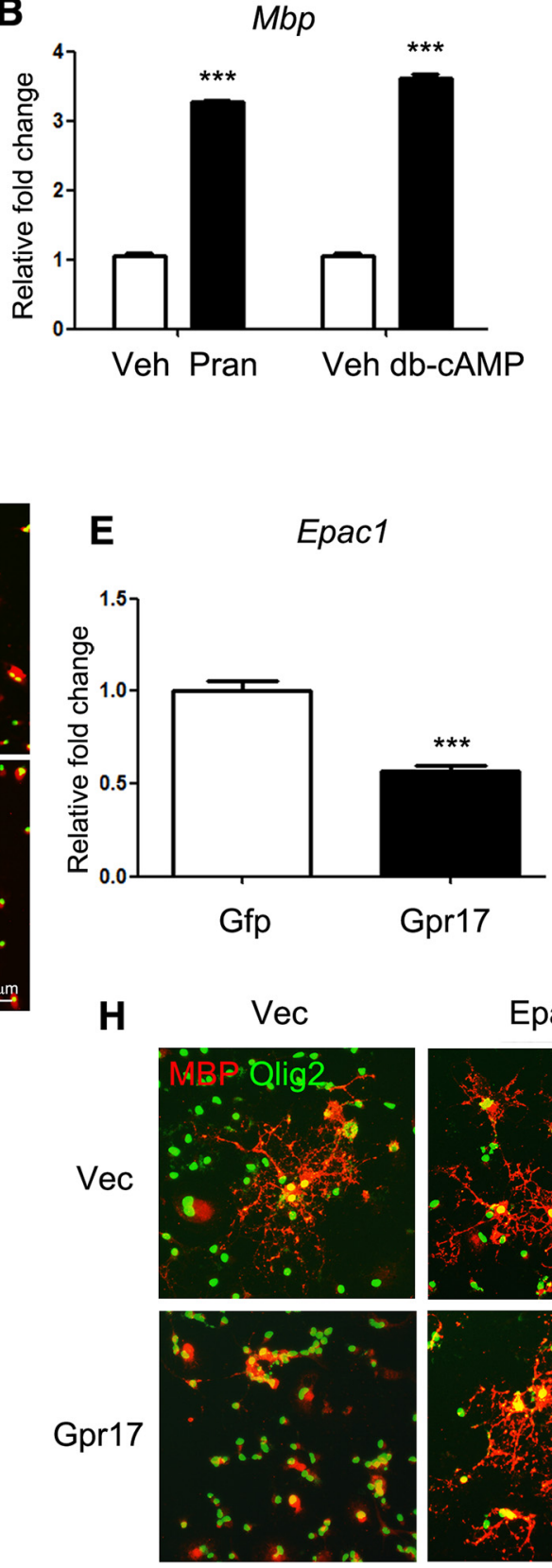

C $\quad$ Mbp

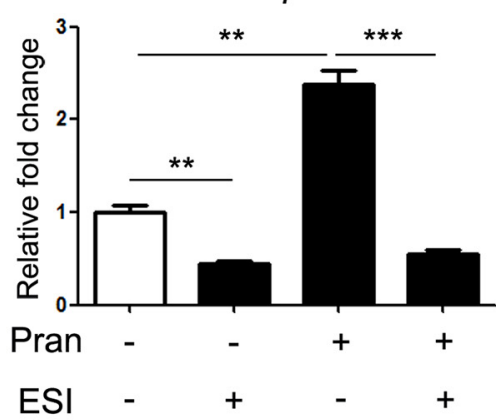

F

Epac1

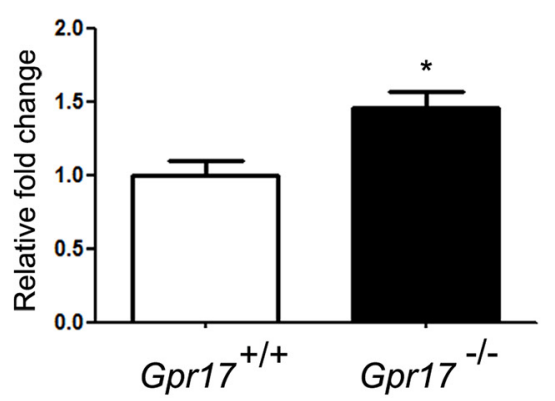

Epac1

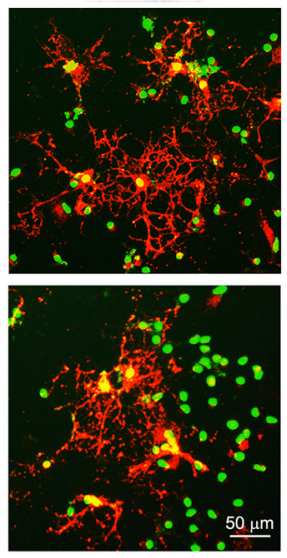

Vec Epac1

Epac1

Gapdh

Figure 7. Gpr17 inhibits oligodendrocyte differentiation via the reduction of Epac1 expression. $A$, Expression of $M b p$ in the total RNA from oligodendrocytes overexpressing Gpr17 or transfected with control vector. Primary rat OPCs were transfected and cultured in the differentiation medium for $48 \mathrm{~h}$. Data are means \pm SEM from three independent experiments. ${ }^{* * *} p<0.001$, Student's $t$ test. $\boldsymbol{B}$, Expression of $M b p$ in the total RNA from oligodendrocytes treated with $10 \mu \mathrm{m}$ pranlukast or $0.5 \mathrm{~mm}$ dibutyryl cAMP in the differentiation medium for $48 \mathrm{~h}$. Data are means \pm SEM from three independent experiments. ${ }^{* * *} p<0.001$, Student's $t$ test. C, Expression of Mbp in the total RNA from oligodendrocytes treated with vehicle, $10 \mu \mathrm{m} \mathrm{pranlukast,} \mathrm{and/or} 20 \mathrm{~mm}$ ESI as indicated in the differentiation medium for $48 \mathrm{~h}$. Data are means \pm SEM from three independent experiments. ${ }^{* *} p<0.01$, ${ }^{* * *} p<0.001$, one-way ANOVA with Tukey's multiple-comparison test. $\boldsymbol{D}$, Immunofluorescent staining of Olig2 and MBP in oligodendrocytes cultured in vehicle, $10 \mathrm{~mm}$ pranlukast, and/or $20 \mathrm{~mm}$ ESI in the differentiation medium for $48 \mathrm{~h}$. Scale bar, $50 \mu \mathrm{m}$. E, Expression of Epac1 in the total RNA from oligodendrocytes overexpressing Gpr17 or transfected with control vector. Primary rat OPCs were transfected and cultured in the differentiation medium for $48 \mathrm{~h}$. Data are means \pm SEM from three independent experiments. ${ }^{* * *} p<0.001$, Student's $t$ test. $F$, Expression of Epac1 in the total RNA from the whole brains of Gpr $17^{+/+}$or Gpr $17^{-1-}$ mice at 8 weeks of age $\left(n=8\right.$ animals per genotype). ${ }^{*} p<0.05$, Student's $t$ test. $\mathbf{G}$, Expression of Epac 1 in the total RNA from oligodendrocytes treated with $0.5 \mathrm{~mm}$ dibutyryl cAMP or $10 \mu \mathrm{m}$ pranlukast in the differentiation medium for $48 \mathrm{~h}$. Data are means \pm SEM from three independent experiments. ${ }^{*} p<0.05,{ }^{* * *} p<0.001$, one-way ANOVA with Tukey's multiple-comparison test. $\boldsymbol{H}$, Primary rat OPCs were transfected with control vector, Gpr17, and/or Epac1-expressing vectors and cultured in the differentiation medium for $48 \mathrm{~h}$. Left, Immunofluorescent staining of MBP and Olig2. Right, Overexpression of Epac1 was assessed by Western blot analysis. Scale bar, $50 \mu \mathrm{m}$. Veh, Vehicle; Pran, pranlukast; db-cAMP, dibutyryl cAMP,

was bred with oligodendrocyte-expressing Olig1-Cre line to evaluate the Gpr17 function in the development of oligodendrocyte lineage cells (Fig. 8A). Consistent with our previous report, the

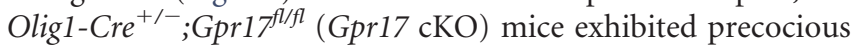
myelination at the neonatal stage P0 (Fig. 8B). In adulthood, myelinogenesis was comparable between control and Gpr17 cKO mice as indicated by the integrity of the myelin sheath ultrastructure in the corpus callosum (Fig. 8C). Moreover, the populations of mature oligodendrocytes $\left(\mathrm{MBP}^{+}, \mathrm{CC}^{+}\right)$, OPCs $\left(\mathrm{PDGFR} \alpha^{+}\right)$, neurons $\left(\mathrm{NeuN}^{+}\right)$, reactive astrocytes $\left(\mathrm{GFAP}^{+}\right)$, and microglia $\left(\mathrm{Ibal}^{+}\right)$were not affected in Gpr17null or Gpr17 cKO mice (Fig. 8D). 
A

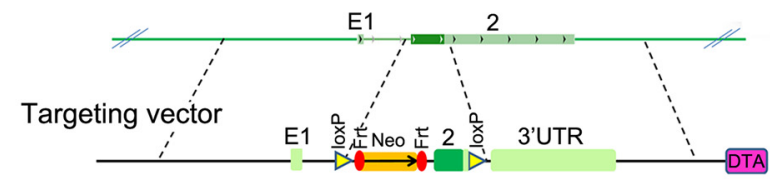

B

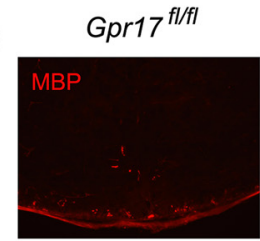

Gpr17 cKO

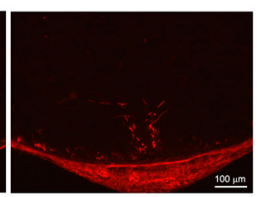

\section{D}
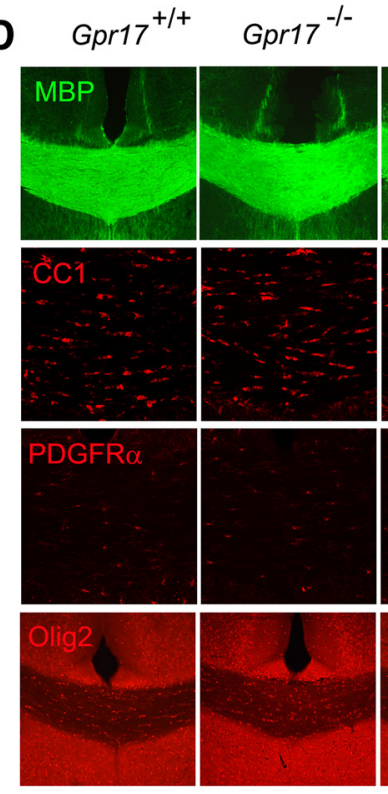

Gpr17 cKO
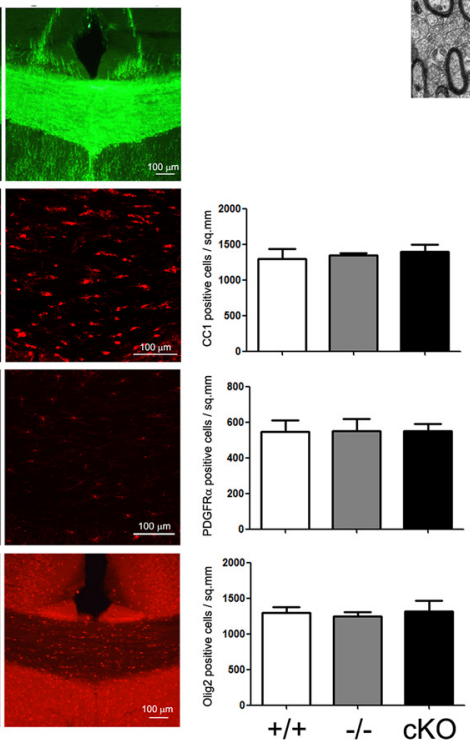
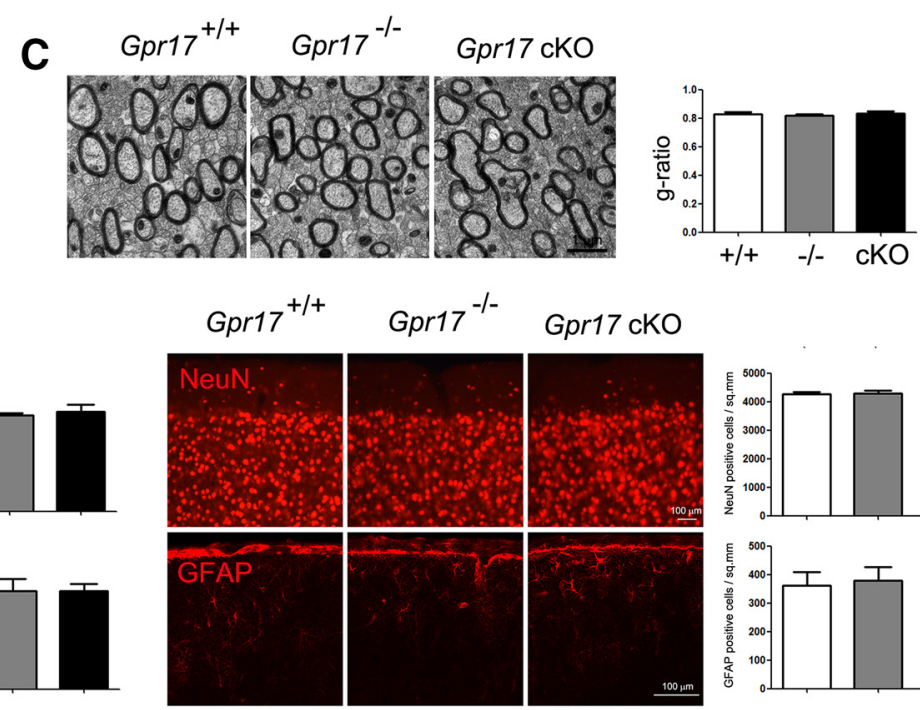

$\mathrm{Gpr}_{17^{-/-}}$

Gpr17 cKO
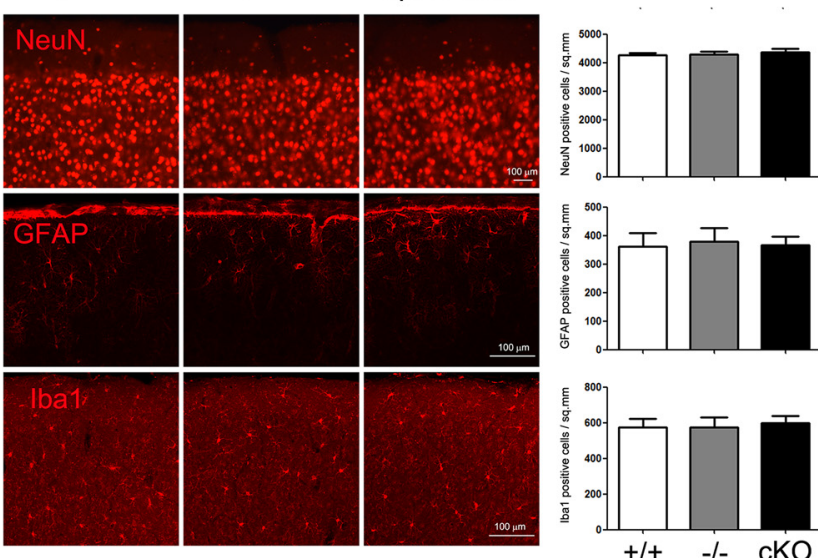
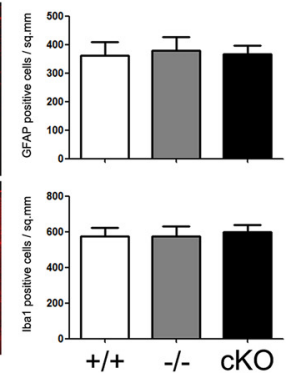

Figure 8. Gpr17 ablation in adulthood has no effect on myelinogenesis. $\boldsymbol{A}$, Schematic strategy for the generation of the Gpr $17^{f / f l}$ mouse strain. $\boldsymbol{B}$, Immunofluorescent staining for MBP of spinal cord sections from wild-type and Gpr 17 CKO mice at PO ( $n=5$ animals per genotype). Scale bar, $100 \mu \mathrm{m}$. C, Electron microscopic examination of the corpus callosum of wild-type, Gpr $17^{-1-}$, and Gpr17 CKO mice at 8 weeks of age ( $n=5$ animals per genotype). Scale bar, $1 \mu \mathrm{m}$. D, Immunofluorescent staining using the indicated antibodies of brain sections from wild-type, $G$ pr $17^{-1-}$, and Gpr17 cKO mice at 8 weeks of age ( $n=5$ animals per genotype). Scale bar, $100 \mu \mathrm{m}$. Pran, Pranlukast.

In contrast to normal myelination, the role of Gpr17 in oligodendrocyte remyelination is unknown. To determine whether the loss of Gpr17 facilitates remyelination after injury and accelerates the recovery of injured myelin sheaths, LPC was stereotactically injected into the CC of 8-week-old wild-type, Gpr $17^{-1-}$, and Gpr17 cKO mice to trigger demyelination. All mice given injections of LPC exhibited focal lesions in the CC at day 3 (Fig. $9 A, B$ ). The deletion of Gpr17, either globally or specifically in the oligodendrocyte lineage, resulted in an earlier onset of remyelination in mice. Both $G \operatorname{pr} 17^{-1-}$ and Gpr17 cKO mice exhibited substantial remyelination at day 7 after injection, whereas little remyelination was observed in wild-type controls as shown by analysis of the expression of $M b p$ and the number of $\mathrm{CC}^{+}{ }^{+}$differentiated oligodendrocytes (Fig. 9B, C). Despite the discrepancy in the onset of remyelination, all of the mice exhibited complete remyelination at day 21 after injection (Fig. 9B, C).

To explore the therapeutic potential of targeting Gpr17, mice were treated with the Gpr17 inhibitor pranlukast after LPCinduced injury (Fig. 9A). At day 7, the wild-type mice that received pranlukast treatment exhibited a similar extent of remyelination to Gpr17 $7^{-1-}$ and Gpr17 cKO mice (Fig. 9B,C). Therefore, our observations suggest that the loss of Gpr17 accelerates the remyelination process after LPC-induced demyelinating injury.

NG2-positive immature oligodendrocytes were present in the demyelinated areas after LPC treatment of wild-type mice. In the mice subjected to either genetic or pharmacologic Gpr17 inhibition, a greater increase in the number of NG2-positive cells was detected than in wild-type mice at day 7 (Fig. 10A). In Gpr17 mutant mice, we observed a reduction of apoptosis, as indicated by the decrease in the level of cleaved caspase 3 (Fig. 10B). These observations suggest that the reduction of oligodendrocyte apoptosis in mice lacking Gpr17 contributes to the increase in $\mathrm{NG}^{+}$ immature oligodendrocytes.

\section{Discussion}

Genome-wide mapping of the regulators in response to LPC-induced oligodendrocyte injury

Although enhancer landscape analyses have been performed in normal oligodendrocytes and CNS tissues (Cotney et al., 2012; Nord et al., 2013; Yu et al., 2013), these studies have not been conducted in conditions that reflect the demyelination process. Here, we performed genome-wide mapping of the H3K27Acassociated enhancers in oligodendrocytes treated with LPC and identified a cohort of regulatory genes that are activated in response to LPC-induced cell stress and demyelination. These included Olig2, Gmeb2, Psip1, Smad7, Klf6, and Nab1, genes encoding transcription factors that are known to be important regulators of oligodendrocyte lineage development (Lu et al., 2002; Le et al., 2005; Weng et al., 2012; Laitman et al., 2016). Olig2 is among the top-ranking transcription factors associated with the regulation of normal oligodendrocyte function by CISGENOME (Ji et al., 2008). Mapping the genes that are responsive to demy- 
A

LPC

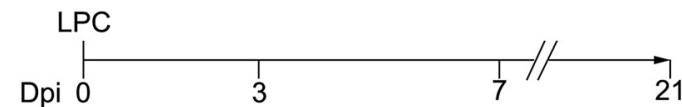

$\mathrm{LPC}+\operatorname{Pran}$

Pran Pran every $12 \mathrm{~h}$

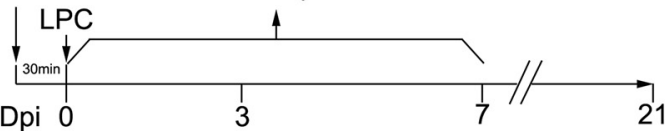

B

0 Dpi

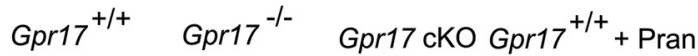

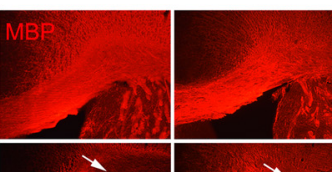

3 Dpi

7 Dpi

$21 \mathrm{Dpi}$
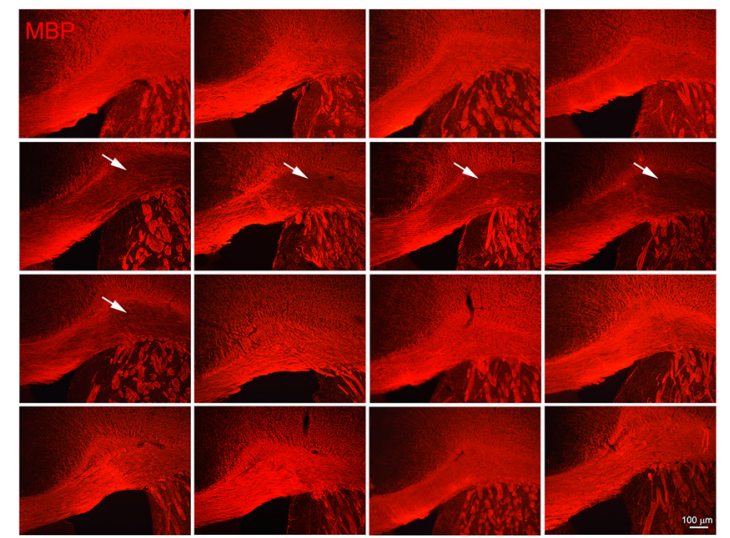

C

0 Dpi

3 Dpi

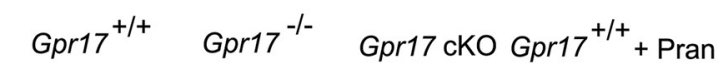

7 Dpi

$21 \mathrm{Dp}$
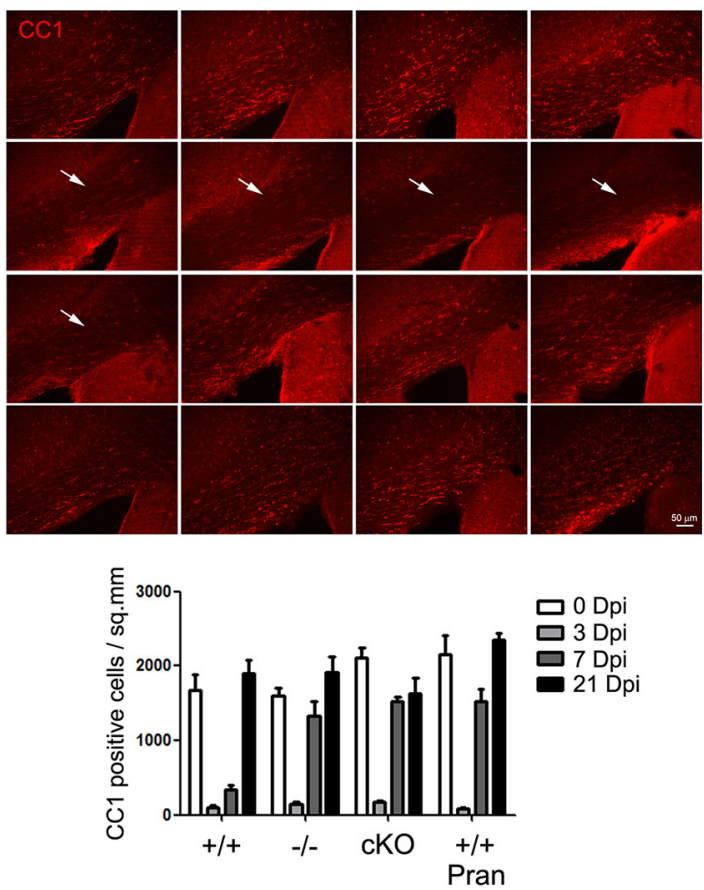

Figure 9. Inhibition of Gpr17 promotes remyelination after LPC-induced myelin injury. $\boldsymbol{A}$, Schematic for LPC treatment and pranlukast treatment in mice at 8 weeks of age. $\boldsymbol{B}$, $\boldsymbol{C}$, $\mathrm{Gpr}^{+1+}$ (WT), Gpr17 ${ }^{-1-}$, and Gpr17 CKO mice were given stereotactic injections of LPC (1\% w/v) in the CC region. For WT mice treated with pranlukast, mice were treated with pranlukast intraperitoneally $30 \mathrm{~min}$ before LPC injection and then every $12 \mathrm{~h}$ thereafter. Immunofluorescent staining for MBP $(\boldsymbol{B})$ and $C(1)(\boldsymbol{C})$ was performed on the brain sections $(n=$ 5 animals per genotype). White arrows indicate the focal lesions. Scale bars: $\boldsymbol{B}, 100 \mu \mathrm{m} ; \boldsymbol{C}, 50 \mu \mathrm{m}$. Pran, Pranlukast; Dpi, day post injection.

A
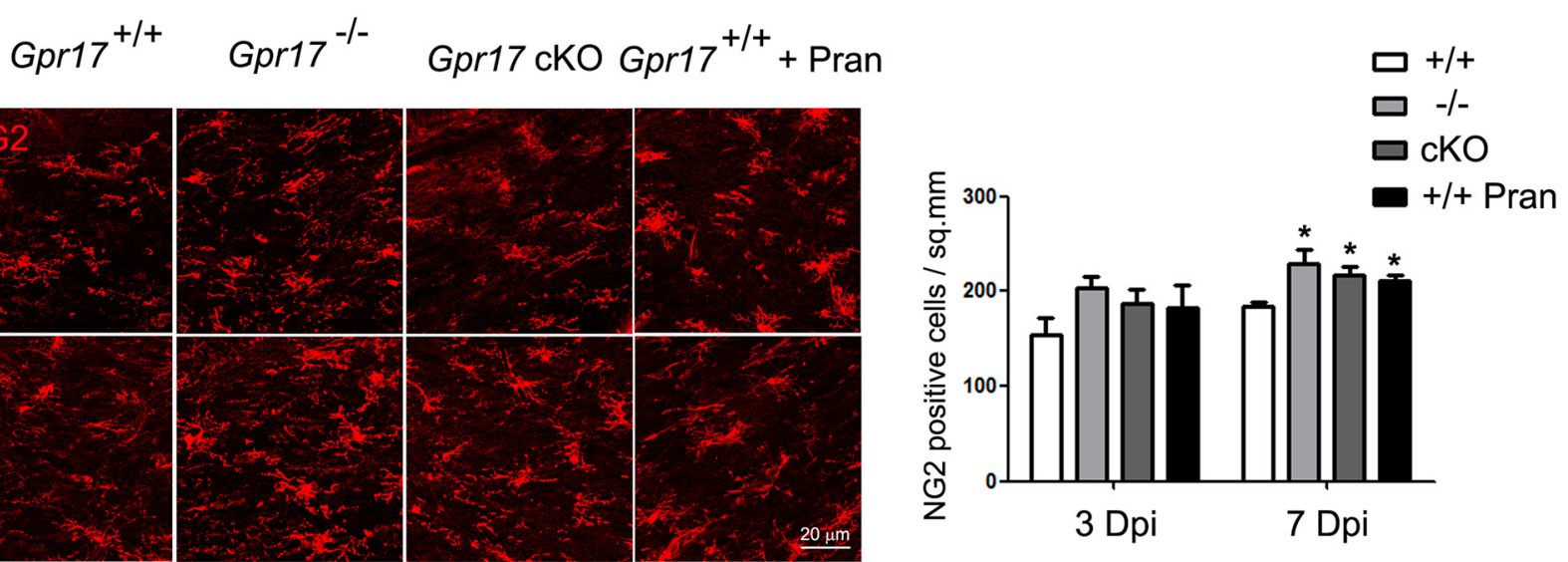

B

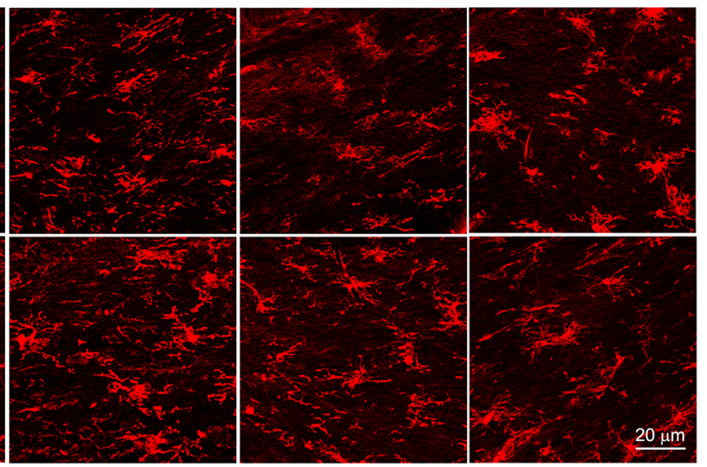

\section{B \\ Cleaved- Caspase3 Gapdh} $\operatorname{Gpr17}^{+/+}$ $\mathrm{Gpr}^{-1-}$ Gpr17 $^{\text {fl/fl }}$ Gpr17 cKO

Figure 10. The inhibition of Gr17 increases the immature oligodendrocyte population at the demyelinating lesion after LPC injection. A, Immunofluorescent staining for NG2 was performed on brain sections of Gpr17 ${ }^{+/+}$(WT), Gpr17 ${ }^{-1-}$, and Gpr17 CKO mice and WT mice treated with pranlukast ( $n=5$ animals per genotype). ${ }^{*} p<0.05$, two-way ANOVA. $B$, Western blot analysis of cleaved caspase 3 in the brains from WT, Gpr17 ${ }^{-1-}, G p r 17^{f / f f l}$, and Gpr17 cK0 mice at 8 weeks of age ( $n=6$ animals per genotype). Pran, Pranlukast; Dpi, day post injection. 
elinating injury may identify potential therapeutic targets for myelin repair.

We identify Gpr17 as a downstream target of Olig2 in oligodendrocytes after LPC treatment. Gpr17 is a negative regulator of oligodendrocyte differentiation and myelination, and its transcription has been reported to be controlled by external signals (Fratangeli et al., 2013). Gpr17 was at the top of the differentially Olig2-bound genes when oligodendrocytes treated with vehicle and with LPC were compared. Recruitment of Olig2 and H3K27Ac to Gpr17 exons was enhanced after LPC treatment, which indicated that Gpr17 was an Olig2 transcriptional target during demyelination.

Gpr17 is mainly expressed in oligodendrocytes in the CNS. Recent studies indicate that Gpr17 regulates oligodendrocyte development and maturation in a stage-specific manner (Chen et al., 2009). Our analysis indicates that Gpr17 is also important in pathogenic situations. Overexpression of Gpr17 in oligodendrocytes blocks myelinogenesis in transgenic mice, whereas Gpr $17^{-1-}$ mice exhibit an abnormally early onset of myelination during the embryonic stage (Chen et al., 2009). In the present study, we showed that loss of Gpr17 specifically in the oligodendrocyte lineage elicited precocious myelination similar to that observed in $G$ prit $17^{-1-}$ mice.

Gpr17 also has been indicated as a "damage sensor" in brain injury models, including ischemia and pathological brain trauma (Lecca et al., 2008; Ceruti et al., 2009; Boda et al., 2011; Zhao et al., 2012). Interestingly, we found that Gpr17 activation impaired oligodendrocyte survival. The overexpression or activation of Gpr17 resulted in oligodendrocyte apoptosis via the upregulation of the apoptotic gene Xaf1. Our data suggest that Xaf1 mediates the apoptosis-inducing effect of Gpr17, as the silencing of Xaf1 expression rescued oligodendrocyte viability that was impaired by Gpr17 activation.

\section{cAMP mediates the biological effects of Gpr17 in oligodendrocytes}

Activated Gpr17 couples with G $\alpha$ i and reduces intracellular cAMP levels, which subsequently influences downstream signaling. In oligodendrocytes, the activation of PKA signaling caused by elevated intracellular cAMP levels leads to increased cell viability. We found that the regulatory effect of PKA signaling on oligodendrocyte apoptosis was mediated by the downstream target c-Fos. During activation of PKA signaling, CREB is known to be transactivated, which increases the expression of downstream genes, including c-Fos (Boutillier et al., 1992; Tyson et al., 1999). The overexpression of Gpr17 in vitro resulted in decreased c-Fos expression, whereas Gpr17 ablation increased c-Fos expression in vivo. The overexpression of c-Fos dramatically inhibited the expression of Xaf1 and increased the viability of oligodendrocytes. This suggests that Gpr17 activity negatively regulates the expression of c-Fos and activates expression of Xaf1 in oligodendrocytes through a Gpr17-cAMP-PKA-CREB-cFos-Xaf1 regulatory loop.

\section{Loss of Gpr17 accelerates remyelination}

It has recently been reported that cAMP accelerates oligodendrocyte differentiation through PKA activation and Epac1 (Simon et al., 2016). We found that the expression of Epacl is negatively regulated by Gpr17. It was previously demonstrated that Gpr17positive OPCs differentiate more slowly than Gpr17-negative OPCs (Viganò et al., 2016).

In this study, we found that deletion of Gpr17, either globally or in the oligodendrocyte lineage, resulted in an earlier onset of remyelination than observed in wild-type animals. Loss of Gpr17 elevated the number of NG2-positive immature oligodendrocytes at LPC-induced lesions, which was likely attributable to an increase of oligodendrocyte survival in Gpr17 mutants. Moreover, Gpr17 inhibition also promoted immature oligodendrocyte differentiation by upregulation of Epac1. The inhibition of Gpr17 activity acts via cAMP and Epac1 pathways to enhance oligodendrocyte survival and promote oligodendrocyte differentiation and myelination. Thus, both enhancement of immature oligodendrocyte survival and increased maturation contribute to the accelerated remyelination in Gpr17 mutants.

To investigate the therapeutic utility of Gpr17 inhibition, we used animal models in which Gpr17 activity was pharmacologically inhibited by pranlukast. Pranlukast is widely used for its antiasthmatic and anti-inflammatory properties (Yamauchi et al., 2001) and has been reported to have neuroprotective properties in conditions of ischemia and cold injury to the brain (Zhang et al., 2002; Shi et al., 2012). Pranlukast treatment of mice given LPC effectively elevated intracellular cAMP levels in oligodendrocytes and enhanced oligodendrocyte survival and remyelination. Thus, our data suggest that Gpr17 inhibition has potential for treatment of demyelinating disease.

\section{References}

Aktas O, Kieseier B, Hartung HP (2010) Neuroprotection, regeneration and immunomodulation: broadening the therapeutic repertoire in multiple sclerosis. Trends Neurosci 33:140-152. CrossRef Medline

Baumann N, Pham-Dinh D (2001) Biology of oligodendrocyte and myelin in the mammalian central nervous system. Physiol Rev 81:871-927. Medline

Berger J, Moser HW, Forss-Petter S (2001) Leukodystrophies: recent developments in genetics, molecular biology, pathogenesis and treatment. Curr Opin Neurol 14:305-312. CrossRef Medline

Birnbaum RY, Clowney EJ, Agamy O, Kim MJ, Zhao J, Yamanaka T, Pappalardo Z, Clarke SL, Wenger AM, Nguyen L, Gurrieri F, Everman DB, Schwartz CE, Birk OS, Bejerano G, Lomvardas S, Ahituv N (2012) Coding exons function as tissue-specific enhancers of nearby genes. Genome Res 22:1059-1068. CrossRef Medline

Boda E, Viganò F, Rosa P, Fumagalli M, Labat-Gest V, Tempia F, Abbracchio MP, Dimou L, Buffo A (2011) The GPR17 receptor in NG2 expressing cells: focus on in vivo cell maturation and participation in acute trauma and chronic damage. Glia 59:1958-1973. CrossRef Medline

Boutillier AL, Barthel F, Roberts JL, Loeffler JP (1992) Beta-adrenergic stimulation of $\mathrm{CFOS}$ via protein kinase A is mediated by cAMP regulatory element binding protein (CREB)-dependent and tissue-specific CREBindependent mechanisms in corticotrope cells. J Biol Chem 267:2352023526. Medline

Byun DS, Cho K, Ryu BK, Lee MG, Kang MJ, Kim HR, Chi SG (2003) Hypermethylation of XIAP-associated factor 1, a putative tumor suppressor gene from the 17p13.2 locus, in human gastric adenocarcinomas. Cancer Res 63:7068-7075. Medline

Ceruti S, Villa G, Genovese T, Mazzon E, Longhi R, Rosa P, Bramanti P, Cuzzocrea S, Abbracchio MP (2009) The P2Y-like receptor GPR17 as a sensor of damage and a new potential target in spinal cord injury. Brain 132:2206-2218. CrossRef Medline

Chan CB, Liu X, Zhao L, Liu G, Lee CW, Feng Y, Ye K (2014) PIKE is essential for oligodendroglia development and CNS myelination. Proc Natl Acad Sci U S A 111:1993-1998. CrossRef Medline

Chen Y, Balasubramaniyan V, Peng J, Hurlock EC, Tallquist M, Li J, Lu QR (2007) Isolation and culture of rat and mouse oligodendrocyte precursor cells. Nat Protoc 2:1044-1051. CrossRef Medline

Chen Y, Wu H, Wang S, Koito H, Li J, Ye F, Hoang J, Escobar SS, Gow A, Arnett HA, Trapp BD, Karandikar NJ, Hsieh J, Lu QR (2009) The oligodendrocyte-specific G protein-coupled receptor GPR17 is a cellintrinsic timer of myelination. Nat Neurosci 12:1398-1406. CrossRef Medline

Ciana P, Fumagalli M, Trincavelli ML, Verderio C, Rosa P, Lecca D, Ferrario S, Parravicini C, Capra V, Gelosa P, Guerrini U, Belcredito S, Cimino M, Sironi L, Tremoli E, Rovati GE, Martini C, Abbracchio MP (2006) The orphan receptor GPR17 identified as a new dual uracil 
nucleotides/cysteinyl-leukotrienes receptor. EMBO J 25:4615-4627. CrossRef Medline

Cotney J, Leng J, Oh S, DeMare LE, Reilly SK, Gerstein MB, Noonan JP (2012) Chromatin state signatures associated with tissue-specific gene expression and enhancer activity in the embryonic limb. Genome Res 22:1069-1080. CrossRef Medline

Creyghton MP, Cheng AW, Welstead GG, Kooistra T, Carey BW, Steine EJ, Hanna J, Lodato MA, Frampton GM, Sharp PA, Boyer LA, Young RA, Jaenisch R (2010) Histone H3K27Ac separates active from poised enhancers and predicts developmental state. Proc Natl Acad Sci U S A 107: 21931-21936. CrossRef Medline

Daniele S, Trincavelli ML, Fumagalli M, Zappelli E, Lecca D, Bonfanti E, Campiglia P, Abbracchio MP, Martini C (2014) Does GRK-beta arrestin machinery work as a "switch on" for GPR17-mediated activation of intracellular signaling pathways? Cell Signal 26:1310-1325. CrossRef Medline

Fancy SP, Chan JR, Baranzini SE, Franklin RJ, Rowitch DH (2011) Myelin regeneration: a recapitulation of development? Annu Rev Neurosci 34: 21-43. CrossRef Medline

Franke H, Parravicini C, Lecca D, Zanier ER, Heine C, Bremicker K, Fumagalli M, Rosa P, Longhi L, Stocchetti N, De Simoni MG, Weber M, Abbracchio MP (2013) Changes of the GPR17 receptor, a new target for neurorepair, in neurons and glial cells in patients with traumatic brain injury. Purinergic Signal 9:451-462. CrossRef Medline

Franklin RJ (2002) Remyelination of the demyelinated CNS: the case for and against transplantation of central, peripheral and olfactory glia. Brain Res Bull 57:827-832. CrossRef Medline

Franklin RJ, ffrench-Constant C (2008) Remyelination in the CNS: from biology to therapy. Nat Rev Neurosci 9:839-855. CrossRef Medline

Franklin RJ, Gallo V (2014) The translational biology of remyelination: past, present, and future. Glia 62:1905-1915. CrossRef Medline

Fratangeli A, Parmigiani E, Fumagalli M, Lecca D, Benfante R, Passafaro M, Buffo A, Abbracchio MP, Rosa P (2013) The regulated expression, intracellular trafficking, and membrane recycling of the P2Y-like receptor GPR17 in Oli-neu oligodendroglial cells. J Biol Chem 288:5241-5256. CrossRef Medline

Fressinaud C (2005) Repeated injuries dramatically affect cells of the oligodendrocyte lineage: effects of PDGF and NT-3 in vitro. Glia 49:555-566. CrossRef Medline

Fressinaud C, Eyer J (2014) Neurofilament-tubulin binding site peptide NFL-TBS.40-63 increases the differentiation of oligodendrocytes in vitro and partially prevents them from lysophosphatidyl choline toxiciy. J Neurosci Res 92:243-253. CrossRef Medline

Hartung HP, Aktas O (2011) Evolution of multiple sclerosis treatment: next generation therapies meet next generation efficacy criteria. Lancet Neurol 10:293-295. CrossRef Medline

Heintzman ND, Hon GC, Hawkins RD, Kheradpour P, Stark A, Harp LF, Ye Z, Lee LK, Stuart RK, Ching CW, Ching KA, Antosiewicz-Bourget JE, Liu H, Zhang X, Green RD, Lobanenkov VV, Stewart R, Thomson JA, Crawford GE, Kellis M, et al. (2009) Histone modifications at human enhancers reflect global cell-type-specific gene expression. Nature 459:108-112. CrossRef Medline

Hennen S, Wang H, Peters L, Merten N, Simon K, Spinrath A, Blättermann S, Akkari R, Schrage R, Schröder R, Schulz D, Vermeiren C, Zimmermann K, Kehraus S, Drewke C, Pfeifer A, König GM, Mohr K, Gillard M, Müller $\mathrm{CE}$, et al. (2013) Decoding signaling and function of the orphan $\mathrm{G}$ protein-coupled receptor GPR17 with a small-molecule agonist. Sci Signal 6:ra93. CrossRef Medline

Ji H, Jiang H, Ma W, Johnson DS, Myers RM, Wong WH (2008) An integrated software system for analyzing ChIP-chip and ChIP-seq data. Nat Biotechnol 26:1293-1300. CrossRef Medline

Laitman BM, Asp L, Mariani JN, Zhang J, Liu J, Sawai S, Chapouly C, Horng S, Kramer EG, Mitiku N, Loo H, Burlant N, Pedre X, Hara Y, Nudelman G, Zaslavsky E, Lee YM, Braun DA, Lu QR, Narla G, et al. (2016) The transcriptional activator Krüppel-like factor-6 is required for CNS myelination. PLoS Biol 14:e1002467. CrossRef Medline

Le N, Nagarajan R, Wang JY, Svaren J, LaPash C, Araki T, Schmidt RE, Milbrandt J (2005) Nab proteins are essential for peripheral nervous system myelination. Nat Neurosci 8:932-940. CrossRef Medline

Lecca D, Trincavelli ML, Gelosa P, Sironi L, Ciana P, Fumagalli M, Villa G, Verderio C, Grumelli C, Guerrini U, Tremoli E, Rosa P, Cuboni S, Martini C, Buffo A, Cimino M, Abbracchio MP (2008) The recently identified
P2Y-like receptor GPR17 is a sensor of brain damage and a new target for brain repair. PLoS One 3:e3579. CrossRef Medline

Liang K, Keles S (2012) Detecting differential binding of transcription factors with ChIP-seq. Bioinformatics 28:121-122. CrossRef Medline

Lu QR, Sun T, Zhu Z, Ma N, Garcia M, Stiles CD, Rowitch DH (2002) Common developmental requirement for Olig function indicates a motor neuron/oligodendrocyte connection. Cell 109:75-86. CrossRef Medline

Marschallinger J, Schäffner I, Klein B, Gelfert R, Rivera FJ, Illes S, Grassner L, Janssen M, Rotheneichner P, Schmuckermair C, Coras R, Boccazzi M, Chishty M, Lagler FB, Renic M, Bauer HC, Singewald N, Blümcke I, Bogdahn U, Couillard-Despres S, et al. (2015) Structural and functional rejuvenation of the aged brain by an approved anti-asthmatic drug. Nat Commun 6:8466. CrossRef Medline

Nord AS, Blow MJ, Attanasio C, Akiyama JA, Holt A, Hosseini R, Phouanenavong S, Plajzer-Frick I, Shoukry M, Afzal V, Rubenstein JL, Rubin EM, Pennacchio LA, Visel A (2013) Rapid and pervasive changes in genomewide enhancer usage during mammalian development. Cell 155:15211531. CrossRef Medline

Pfeiffer SE, Warrington AE, Bansal R (1993) The oligodendrocyte and its many cellular processes. Trends Cell Biol 3:191-197. CrossRef Medline

Rada-Iglesias A, Bajpai R, Swigut T, Brugmann SA, Flynn RA, Wysocka J (2011) A unique chromatin signature uncovers early developmental enhancers in humans. Nature 470:279-283. CrossRef Medline

Ritter DI, Dong Z, Guo S, Chuang JH (2012) Transcriptional enhancers in protein-coding exons of vertebrate developmental genes. PLoS One 7:e35202. CrossRef Medline

Shi QJ, Xiao L, Zhao B, Zhang XY, Wang XR, Xu DM, Yu SY, Fang SH, Lu YB, Zhang WP, Sa XY, Wei EQ (2012) Intracerebroventricular injection of HAMI 3379, a selective cysteinyl leukotriene receptor 2 antagonist, protects against acute brain injury after focal cerebral ischemia in rats. Brain Res 1484:57-67. CrossRef Medline

Simon K, Hennen S, Merten N, Blättermann S, Gillard M, Kostenis E, Gomeza J (2016) The orphan G protein-coupled receptor GPR17 negatively regulates oligodendrocyte differentiation via Galphai/o and its downstream effector molecules. J Biol Chem 291:705-718. CrossRef Medline

Suda N, Itoh T, Nakato R, Shirakawa D, Bando M, Katou Y, Kataoka K, Shirahige K, Tickle C, Tanaka M (2014) Dimeric combinations of MafB, cFos and cJun control the apoptosis-survival balance in limb morphogenesis. Development 141:2885-2894. CrossRef Medline

Sun PH, Zhu LM, Qiao MM, Zhang YP, Jiang SH, Wu YL, Tu SP (2011) The XAF1 tumor suppressor induces autophagic cell death via upregulation of Beclin-1 and inhibition of Akt pathway. Cancer Lett 310:170-180. CrossRef Medline

Trapp BD, Peterson J, Ransohoff RM, Rudick R, Mörk S, Bö L (1998) Axonal transection in the lesions of multiple sclerosis. N Engl J Med 338: 278-285. CrossRef Medline

Tyson DR, Swarthout JT, Partridge NC (1999) Increased osteoblastic c-Fos expression by parathyroid hormone requires protein kinase A phosphorylation of the cyclic adenosine $3^{\prime}, 5^{\prime}$-monophosphate response elementbinding protein at serine 133. Endocrinology 140:1255-1261. CrossRef Medline

Viganò F, Schneider S, Cimino M, Bonfanti E, Gelosa P, Sironi L, Abbracchio MP, Dimou L (2016) GPR17 expressing NG2-Glia: oligodendrocyte progenitors serving as a reserve pool after injury. Glia 64:287-299. CrossRef Medline

Weng Q, Chen Y, Wang H, Xu X, Yang B, He Q, Shou W, Chen Y, Higashi Y, van den Berghe V, Seuntjens E, Kernie SG, Bukshpun P, Sherr EH, Huylebroeck D, Lu QR (2012) Dual-mode modulation of Smad signaling by Smad-interacting protein Sip1 is required for myelination in the central nervous system. Neuron 73:713-728. CrossRef Medline

Yamauchi K, Tanifuji Y, Pan LH, Yoshida T, Sakurai S, Goto S, Kuroda S, Kobayashi H, Inoue H (2001) Effects of pranlukast, a leukotriene receptor antagonist, on airway inflammation in mild asthmatics. J Asthma 38:51-57. CrossRef Medline

Yu Y, Chen Y, Kim B, Wang H, Zhao C, He X, Liu L, Liu W, Wu LM, Mao M, Chan JR, Wu J, Lu QR (2013) Olig2 targets chromatin remodelers to enhancers to initiate oligodendrocyte differentiation. Cell 152:248-261. CrossRef Medline 
Yue T, Xian K, Hurlock E, Xin M, Kernie SG, Parada LF, Lu QR (2006) A critical role for dorsal progenitors in cortical myelination. J Neurosci 26:1275-1280. CrossRef Medline

Zhang W, Guo Z, Jiang B, Niu L, Xia G, Wang X, Cheng T, Zhang Y, Wang J (2010) Identification of a functional p53 responsive element within the promoter of XAF1 gene in gastrointestinal cancer cells. Int J Oncol 36: 1031-1037. Medline

Zhang WP, Wei EQ, Mei RH, Zhu CY, Zhao MH (2002) Neuroprotective effect of ONO-1078, a leukotriene receptor antagonist, on focal cerebral ischemia in rats. Acta Pharmacol Sin 23:871-877. Medline

Zhao B, Zhao CZ, Zhang XY, Huang XQ, Shi WZ, Fang SH, Lu YB, Zhang WP, Xia Q, Wei EQ (2012) The new P2Y-like receptor G proteincoupled receptor 17 mediates acute neuronal injury and late microgliosis after focal cerebral ischemia in rats. Neuroscience 202:42-57. CrossRef Medline

Zhou Q, Anderson DJ (2002) The bHLH transcription factors OLIG2 and OLIG1 couple neuronal and glial subtype specification. Cell 109:61-73. CrossRef Medline

Zhu LM, Shi DM, Dai Q, Cheng XJ, Yao WY, Sun PH, Ding Y, Qiao MM, Wu YL, Jiang SH, Tu SP (2014) Tumor suppressor XAF1 induces apoptosis, inhibits angiogenesis and inhibits tumor growth in hepatocellular carcinoma. Oncotarget 5:5403-5415. CrossRef Medline

Zou B, Chim CS, Pang R, Zeng H, Dai Y, Zhang R, Lam CS, Tan VP, Hung IF, Lan HY, Wong BC (2012) XIAP-associated factor 1 (XAF1), a novel target of $\mathrm{p} 53$, enhances $\mathrm{p} 53$-mediated apoptosis via post-translational modification. Mol Carcinog 51:422-432. CrossRef Medline 